See discussions, stats, and author profiles for this publication at: https://www.researchgate.net/publication/320863997

\title{
PISA: New Design Methods for Offshore Wind Turbine Monopiles
}

Conference Paper · September 2017

CITATIONS

22

22 authors, including:

Ay Byron W. Byrne

University of Oxford

90 PUBLICATIONS 2,300 CITATIONS

SEE PROFILE

27) Harvey Burd

1. University of Oxford

119 PUBlicATIONS 1,395 CITATIONS

SEE PROFILE
READS

4,193

Some of the authors of this publication are also working on these related projects:

(2) University of Oxford

20 PUBLICATIONS 177 CITATIONS

SEE PROFILE

Guy Tinmouth Houlsby

University of Oxford

296 PUBLICATIONS 9,074 CITATIONS

SEE PROFILE

Biomechanics of human eye lenses View project

Risk Analysis of Infrastructure Networks in Response to Extreme Weather (RAIN) View project 


\title{
OFFSHORE SITE INVESTIGATION AND GEOTECHNICS
}

\section{SMARTER SOLUTIONS FOR FUTURE OFFSHORE DEVELOPMENTS}

\author{
Proceedings of the 8th International Conference \\ 12-14 September 2017 \\ Royal Geographical Society, London, UK
}

Jointly sponsored by:

Fugro, Subsea 7, Horizon Geosciences, RPS, Cathie \& Associates, Atkins, Next Geosolutions, MMT, Lloyd's Register, BP, NGI, East Point Geo, Arup, Ternan Energy, Plaxis, Geotek

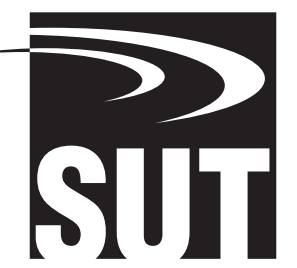

Society for Underwater Technology
Organised by the Offshore Site Investigation and Geotechnics Committee of the Society for Underwater Technology

Published by the Society for Underwater Technology 


\title{
PISA: NEW DESIGN METHODS FOR OFFSHORE WIND TURBINE MONOPILES
}

\author{
BW Byrne, RA McAdam, HJ Burd, GT Houlsby, CM Martin, WJAP Beuckelaers \\ University of Oxford
}
L Zdravkovic, DMG Taborda, DM Potts, RJ Jardine, E Ushev, T Liu, D Abadias
Imperial College London

K Gavin, D Igoe, P Doherty

Formerly University College Dublin

A Muir Wood

\author{
J Skov Gretlund, M Pacheco Andrade \\ DONG Energy Wind Power
}

Formerly DONG Energy Wind Power

FC Schroeder

S Turner, MAL Plummer

Geotechnical Consulting Group

Environmental Scientifics Group

\begin{abstract}
Improved design of laterally loaded monopiles is central to the development of current and future generation offshore wind farms. Previously established design methods have demonstrable shortcomings requiring new ideas and approaches to be developed, specific for the offshore wind turbine sector. The Pile Soil Analysis (PISA) Project, established in 2013, addresses this problem through a range of theoretical studies, numerical analysis and medium scale field testing. The project completed in 2016; this paper summarises the principal findings, illustrated through examples incorporating the Cowden stiff clay profile, which represents one of the two soil profiles targeted in the study. The implications for design are discussed.
\end{abstract}

\section{Introduction}

More than 3500 offshore wind turbines have been installed around European coastlines. Many further installations are planned for the next decade, with substantial reductions in cost needed to ensure economic viability. The majority of existing offshore wind turbines are mounted on monopiles; a single, large diameter, driven pile foundation. These have a simple construction, with an established supply chain and a robust installation process. As the scale of the turbines increases, so too have the piles. Early designs targeted pile diameters $(D)$ around $4 \mathrm{~m}$, with recent designs extending to $8 \mathrm{~m}$ and future designs anticipating diameters of $10 \mathrm{~m}$ or more.

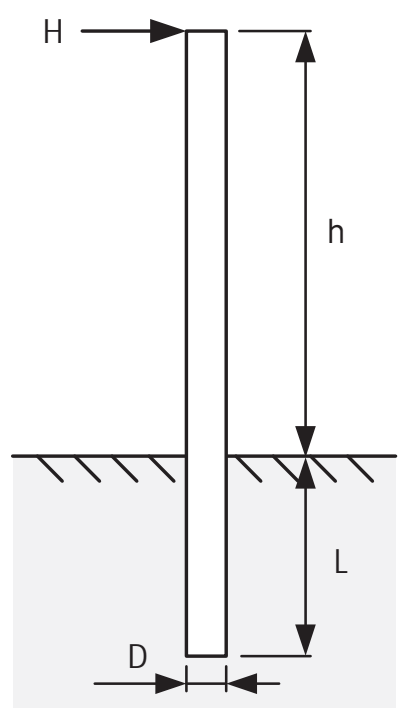

Figure 1: Schematic of the offshore monopile design problem. Wall thickness, $t$, may not be constant with depth of monopile.
Wind loads acting on the turbine and tower, along with wave and current loading on the monopile and transition piece, apply substantial overturning moments to the foundation. Future generation turbines, in deeper water, will impose even greater loads that need to be carried by the monopile foundations. Figure 1 shows a schematic of this design problem with relevant dimensionless groups given in Table 1, developed following the work of Kelly et al. (2006) and LeBlanc et al. (2010).

Table 1: Dimensionless groups for the monopile problem, where $H$ is the horizontal load, $s_{u}$ is undrained shear strength, $G_{0}$ is the small strain shear stiffness, $\sigma^{\prime}{ }_{v i}$ is the vertical effective stress, $v$ is the lateral displacement, $\psi$ is the pile cross section rotation and $p_{a}$ is a reference atmospheric pressure.

Dimensionless expression

\begin{tabular}{lcc} 
& \multicolumn{1}{c}{ Clay } & Sand \\
\cline { 2 - 3 } Horizontal load & $\frac{H}{s_{u} D^{2}}$ & $\frac{H}{\sigma_{v i}^{\prime} D^{2}}$ \\
Lateral deflection & $v / D I_{R}$ & $\frac{v}{D} I_{s} \sqrt{p_{a} / \sigma_{v i}^{\prime}}$ \\
Rotation & $\psi I_{R}$ & $\psi I_{s} \sqrt{p_{a} / \sigma_{v i}^{\prime}}$ \\
Soil stiffness & $I_{R}=G_{0} / s_{u}$ & $I_{s}=G_{0} / \sqrt{p_{a} \sigma_{v i}^{\prime}}$ \\
\hline Embedded length & & $L / D$ \\
Wall thickness & & $D / t$ \\
Height of resultant & & $h / D$ \\
\hline
\end{tabular}




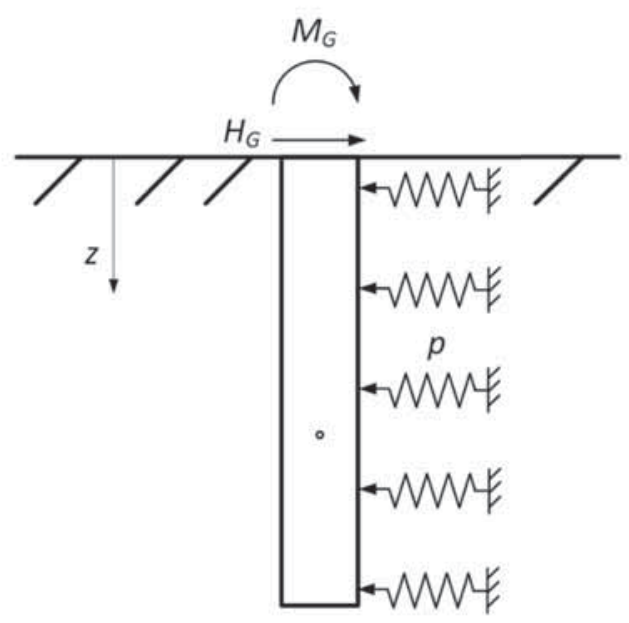

Figure 2: Approximation of soil response to pile loading where $M_{G}$ and $H_{G}$ represent the moment and horizontal force at ground level.

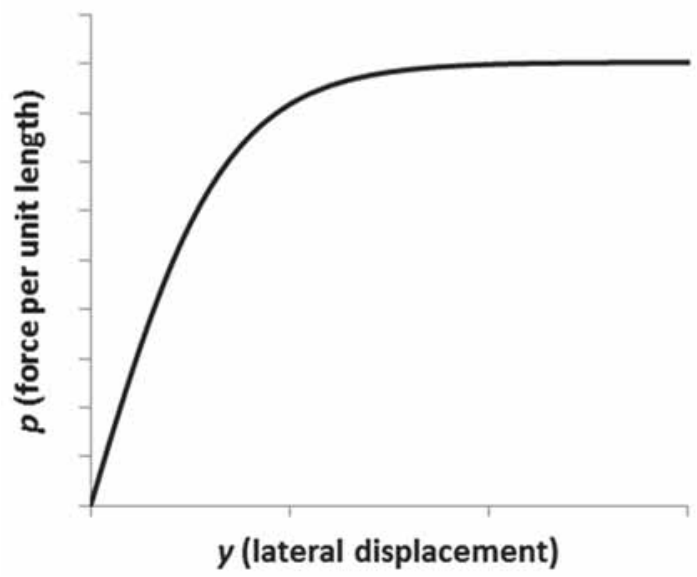

Figure 3: Typical p-y non-linear elastic soil reaction curve.

\subsection{Current design methods}

Piles subject to lateral and overturning loads are typically designed using the $p-y$ method, which is based on a Winkler approach (Winkler, 1867) and is recommended in many of the offshore design codes (e.g. DNVGL, 2016; API, 2010). In this method the pile is treated as a beam supported by independent non-linear elastic springs, which represent the local lateral soil reactions, similar to that shown in Figure 2. The spring soil reaction, $p$, at a given depth is normally described as a function of the lateral displacement, $y$, using non-linear functions (known as $p-y$ curves), as shown in Figure 3. Initially developed in the 1950s and 1960s, the $p-y$ method has a long history of application to pile design for offshore oil and gas structures. Field testing campaigns, measuring the response of long slender piles with diameters around $610 \mathrm{~mm}$ and a length to diameter ratio of 34 , were used to infer the original $p-y$ curves (Reese and Matlock, 1956; Matlock, 1970; Reese et al., 1974; Cox et al., 1974).

The design of offshore oil and gas structures, which is principally aimed at avoiding collapse, is routinely carried out using the $p-y$ approach. However in recent years, the $p-y$ approach has increasingly been applied to the design of large diameter monopiles which typically have relatively small length to diameter ratios. These geometries fall significantly outside of the parameter space of the original calibration field tests, so it is unclear whether extrapolating the $p-y$ method to large diameter monopiles is justified.

\subsection{Limitations of current design methods}

The following uncertainties and concerns arise when the current $p-y$ approaches are applied to the design of wind turbine monopiles:

a) The formulations for the $p-y$ curves specified in the traditional API/DNVGL guidelines are of a generic form. Uncertainties typically exist in the choice of appropriate parameters to calibrate these models for particular applications. In addition, it is unclear how soil constitutive data obtained using modern methods of in situ testing (e.g. small strain stiffness data obtained using seismic cone tests) and laboratory testing (e.g. bender element testing and locally instrumented stress path tests) may be used to assist in the specification of appropriate $p-y$ curves for a particular offshore site.

b) The design of support structures for an offshore wind farm requires significant numbers of load cases to be investigated for many turbines across the wind farm, including time-domain analyses for dynamic response during the operation of the wind turbine, as well as pseudo-static push-over analyses. These calculations focus not only on the ultimate limit state but also the serviceability and fatigue limit states, with a significant emphasis on design against fatigue. The accumulation of fatigue damage within the foundation and support structure is strongly conditioned by the dynamic performance of the system, which, in turn, depends on the stiffness of the foundation. In particular, the assessment of the structural natural frequencies forms an important part of the design process. Uncertainties exist on the extent to which current $p-y$ formulations are able to provide realistic estimates of foundation stiffness for use in dynamic design calculations.

c) Previous researchers (e.g. Davidson, 1982; Lam and Martin, 1986; Gerolymos and Gazetas, 2006; Lam, 2013) have noted that for laterally-loaded caisson and drilled shaft foundations, with values of $L / D$ that correspond to typical offshore monopile geometries, the behaviour of the caisson under lateral loading is influenced by further soil reactions, in addition to the lateral load resistance generated by 


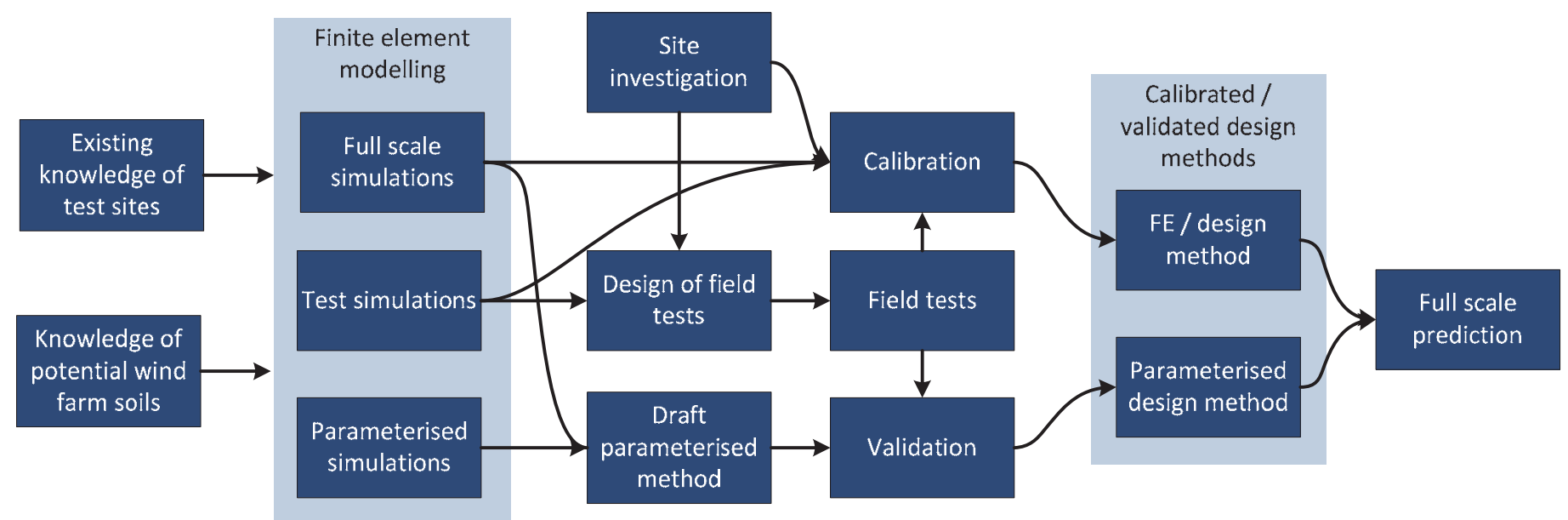

Figure 4: Overview of activity for the PISA Project (Byrne et al., 2015a).

the soil. These include the vertical shear stresses induced on the external perimeter of the foundation as well as a moment and a horizontal force developed across the base of the foundation. These additional soil-pile interaction mechanisms appear to become increasingly significant as the caisson becomes stockier (i.e. as $L / D$ reduces). They therefore can have a significant influence on the behaviour of monopile foundations for offshore wind applications but are omitted in the API/DNVGL $p-y$ approaches.

d) Environmental loads applied to offshore wind turbine structures are typically cyclic in nature. The effect that load cycling might have on the long-term performance of a monopile foundation is a key consideration during the design process. The approach adopted in current recommended practice is to modify the static $p-y$ curves by using appropriate empirical factors effectively to reduce stiffness and strength. While this provides a pragmatic way of extending the static $p-y$ method, it does not reflect the detailed processes that are associated with the degradation or improvement of foundation performance as a consequence of cyclic loading. In particular, such methods take no account of the magnitude of cyclic load or the number of applied cycles. Furthermore, the approach offers no prediction of the accumulation of permanent deflection under cyclic loading.

In recent updates to design guidance, such as in DNVGL (2016), the various shortcomings have been recognised with, for example, a specific suggestion that any proposed design method for large diameter monopiles is validated by other means, such as by finite element (FE) calculations. No detail is provided as to what exercises are needed to validate such design methods.

\subsection{Overview of PISA Project}

To further address the shortcomings the joint industry project, Pile Soil Analysis (PISA), was developed and led by DONG Energy, in partnership with 10 other offshore wind companies, through the Carbon Trust Offshore Wind Accelerator program. The principal activities of the project were executed by an Academic Work Group (AWG), led and managed by Oxford University, partnering with Imperial College London and University College Dublin. The AWG provided the scientific advice to the project, directing and executing the work required to develop the new design methods. A number of consultants and contractors were employed to execute elements of the work (e.g. site investigation, test execution) with approximately 100 people involved in various activities at different stages. An Independent Technical Review Panel was appointed by the project funders to critically review the work developed by the AWG. At an early stage, the project focused on addressing the points a) to c) above but not $\mathrm{d}$ ), principally as any progress on cyclic loading methods first requires a robust approach to the monotonic loading case.

\subsection{Design method development strategy}

A range of options could be pursued to develop a new design approach. The historic (and current) approach, the $p-y$ method, appears to offer many advantages, not only because it is well understood by the industry, but also because it is easy to embed into existing design methods, representing a balance between computational efficiency and model complexity. This approach is further developed in the PISA Project, but extended to include additional components of soil reaction, which are demonstrated to be important for wind turbine monopiles.

The development of the design method is based on detailed three dimensional finite element (3D FE) analyses. In this way the benefits of numerical 
analysis for accurately modelling complexity can be combined with the computational benefits of the existing, conventional $p-y$ framework. The approach is structured so that, as more analyses are completed, the methodology can be updated and improved, with the design method encompassing an entire process, rather than simply prescribing equations. The design method is set out in such a way as to be wholly compatible with current calculation approaches used by structural engineers, enabling the geotechnical response to be accurately captured in the structural analysis.

The detailed execution of the project followed the path described in Figure 4. At the outset it was necessary to select two reference soil materials to constrain the scope of the work, and to focus attention on likely field testing sites. The two materials chosen, stiff clay and dense sand, led to the selection of Cowden (on the north east coast of England) and Dunkirk (in northern France) as test sites. A wide range of FE modelling was undertaken to aid the development of the new design methods and to explore the design of the field test apparatus. This FE modelling made use of both historic soil characterisation data and, latterly, the more recently acquired soil characterisation data collected during the PISA Project. This included a range of in situ testing and laboratory element testing. The design methodology development involved detailed interrogation of the numerical data combined with a rational engineering interpretation of the design problem. Given the relatively short timescale of the project, the numerical modelling, development of the design method and the design of the field testing were run in parallel, but not independently. The field testing provided a clear validation of the numerical modelling, which then formed the basis for the development of the wider design method for large scale monopiles.

\subsection{Timetable for the PISA Project}

The Academic Work Group activity for the PISA Project was advertised by DONG Energy and the Carbon Trust in March 2013. The consortium led by Oxford University with Imperial College London and University College Dublin submitted the successful tender at the end of April 2013, following revisions after interview. The project formally commenced on $1^{\text {st }}$ August 2013.

The key highlights in the timeline include:

- The Project Plan, delivered on $1^{\text {st }}$ September 2013 identified the deficiencies in the existing design methods and outlined a program of work to develop a new design methodology, including the requirements of numerical analysis and a suggested field test campaign.

- The field testing campaign initiated in November 2013, with the release of a tender for test contractors.

- The Draft Methodologies for Clay and Sand, submitted on $1^{\text {st }}$ May 2014 and $1^{\text {st }}$ August 2014 respectively, proposed new design methodologies for the target materials, including a process for obtaining design equations. It was important for the project that the design methods were developed ahead of the field testing program.

- The piles were installed between $14^{\text {th }}$ October 2014 and $9^{\text {th }}$ December 2014. Testing commenced at Cowden on $16^{\text {th }}$ January 2015 with the final pile tested on $21^{\text {st }}$ July 2015. Testing at Dunkirk took place between $22^{\text {nd }}$ April 2015 and $20^{\text {th }}$ June 2015. There was a period of learning during the field testing, with the initial tests at Cowden taking longer than those at Dunkirk. The Field Test Factual Report was submitted on $6^{\text {th }}$ November 2015 , along with digital files of the test data.

- The draft Final Report, submitted on $3^{\text {rd }}$ February 2016, summarised all work carried out on the project, with the recommended design approach for laterally loaded piles. The Final Report, taking account of feedback from funding partners and the independent technical review panel, was submitted on $13^{\text {th }}$ May 2016.

This paper sets out a summary that brings together the different strands of work (advanced laboratory testing, numerical modelling, field testing and design methodology) that have been achieved in PISA, with a focus on the Cowden stiff clay material. Initial discussion of this work can be found in Byrne et al. (2015a, 2015b) and Zdravkovic et al. (2015). It is expected that further details of the work will be published over the next two years; it is therefore appropriate that the following provides an overview of the achievements illustrated by example results. The paper concludes with implications for design.

\section{Sites and Characterisation}

The high level aim of PISA was to provide a new design methodology that can be applied to a variety of sand and clay soils and other materials. However, to constrain the parameter space for the study, and the costs, the research was focused on two reference materials, representing stiff low plasticity clay and dense sand. Two onshore test sites were chosen for the field testing to represent these materials: (a) the Cowden clay site; and (b) the Dunkirk sand site. 

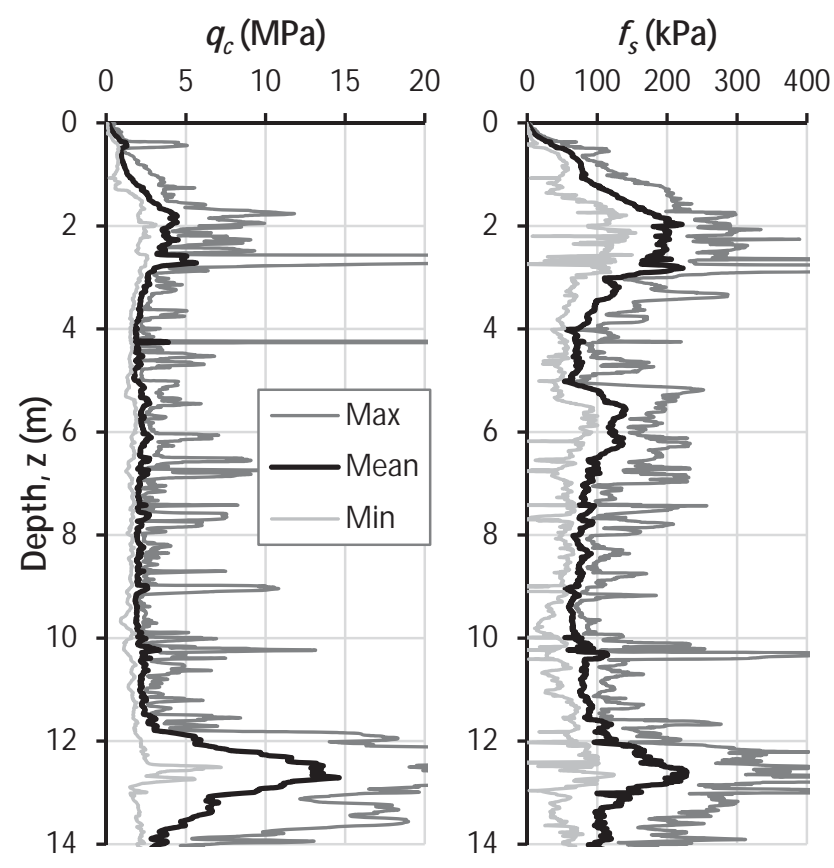

Figure 5: Compilation of CPT results from the Cowden test site.

These sites were deemed to adequately represent (a) glacial, ductile, low plasticity stiff clay and (b) dense sand ground conditions, encountered in some sectors of the North Sea. Both onshore test sites have extensive histories of pile testing activities (e.g. Lehane and Jardine, 1994; Chow, 1997; Jardine et al., 2006), and consequently the sites have been reasonably characterised through field testing and laboratory experiments (e.g. Powell and Butcher, 2003). This makes them excellent reference sites, with the existing knowledge base feeding into the preliminary phase of advanced 3D FE modelling, and additional site characterisation, commissioned during the project, feeding into the final phase of numerical modelling.

(a)

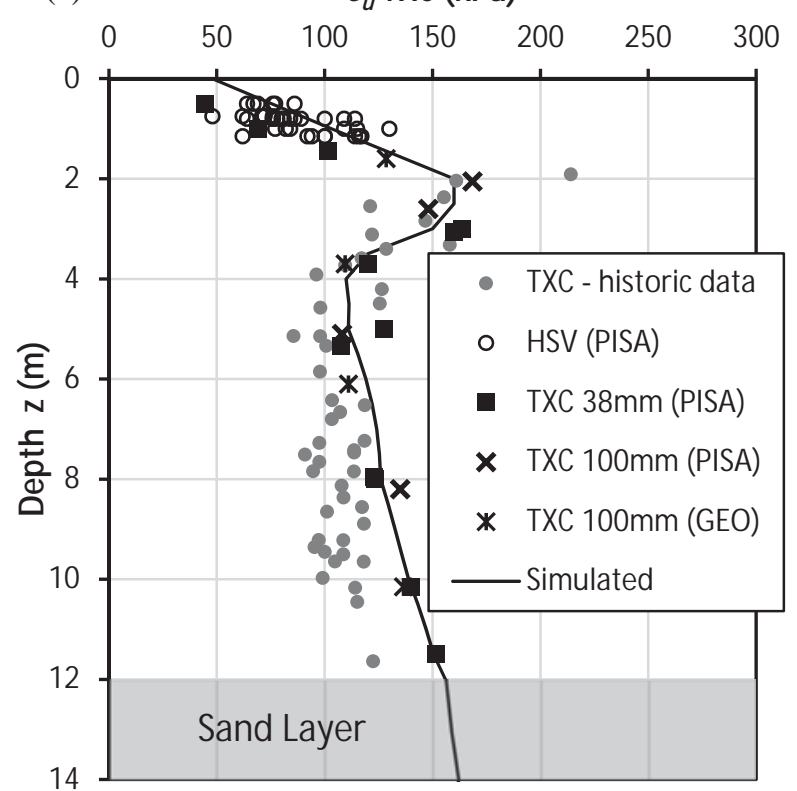

\subsection{Site investigation and laboratory testing}

As part of the SI campaign for the PISA Project, individual $\mathrm{CPTu}$ profiles were determined at each pile location, as well as other locations around the site. A summary of the CPT data is presented in Figure 5, showing the average (mean), maximum and minimum recorded values for all pile locations. The CPT cone resistance traces $\left(q_{c}\right)$ were very consistent across the site, falling in a narrow band and indicating that the superficial deposit has much lower undrained strength than assumed from the historic data at the start of PISA (see discussion in Zdravkovic et al., 2015). At the same time new SCPT profiles, shown in Figure 6(b), indicated higher values of the maximum shear modulus $G_{0}$ than was expected on the basis of the historic data. As a consequence, new laboratory testing programs were commissioned at Imperial College London and GEOLABS, using advanced triaxial apparatus and intact Cowden clay specimens sampled on site, to further examine strength and stiffness of the deposit and aid the derivation of the final set of constitutive model parameters for Cowden clay.

The new soil data, shown in Figure 6(a), from intact triaxial samples (TXC) and hand shear vane (HSV) tests, confirmed lower undrained TXC strength in the top $2 \mathrm{~m}$ by comparison with historic data, but good agreement with the rest of the historic data. The black solid line shows the simulated profile adopted for the numerical analyses presented in this paper.

The interpretation of the maximum shear modulus, $G_{0}$, from the triaxial small strain measurements with local gauges in Figure 6(b) shows a lower $G_{0}$ profile

(b)

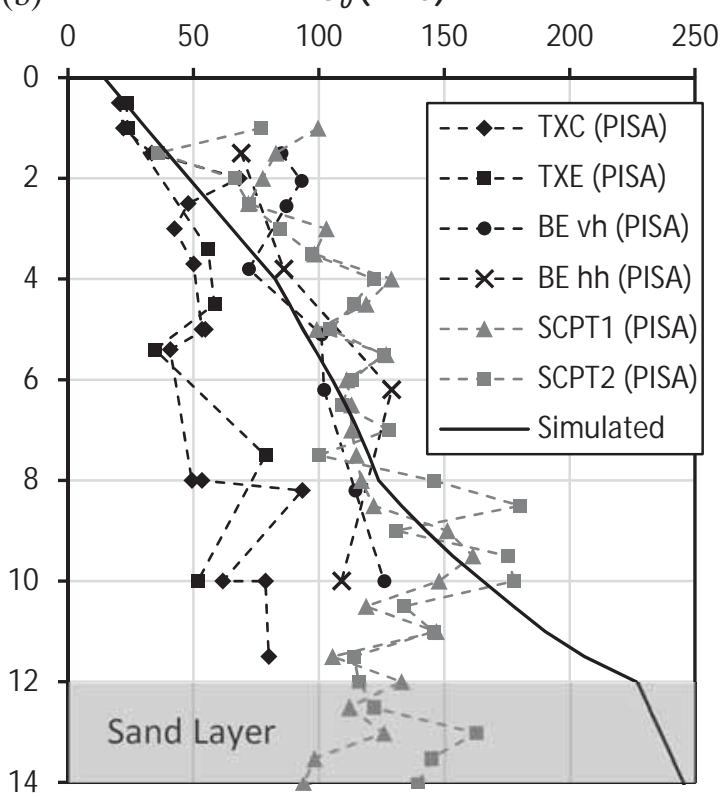

Figure 6: Results of numerical model calibration for the Cowden test site. TXC (triaxial compression test), HSV (hand shear vane), TXE (triaxial extension test), BE (bender element test), $v$ or h (vertical or horizontal), SCPT (seismic cone penetrometer test). 
compared to those interpreted from dynamic measurements, which incorporated bender elements (BEs) and seismic cone penetrations (SCPTs). Both vertically and horizontally propagating shear waves were applied with BEs mounted on intact triaxial samples. These measurements suggested stiffness anisotropy in the elastic region, however no additional testing was performed at the time of the project to fully quantify this, nor the evolution of stiffness anisotropy in the small strain range. Consequently, the shear stiffness is interpreted here as an equivalent isotropic stiffness with the $G_{0}$ profile of $1100 p$ ' adopted for the 3D FE field test analyses. This approximates an upper boundary to the $G_{0}$ interpretation from triaxial small strain measurements, and a lower boundary to that from dynamic measurement techniques.

The clay till deposit is modelled as a single layer, ignoring the presence of the sand layer, at a depth of about $12 \mathrm{~m}$, as shown on the CPT traces depicted in Figure 5. This is justified by the fact that the maximum depth of the test piles is $10.5 \mathrm{~m}$, which is $1.5 \mathrm{~m}$ above the sand layer.

\section{Overview of Numerical Analysis}

The 3D FE modelling for the PISA Project was aimed at: (i) establishing the basis for developing a new design methodology for laterally loaded piles; (ii) identifying mechanisms of pile-soil interaction; and (iii) informing the design of test piles and field testing programs at the chosen clay (Cowden) and sand (Dunkirk) test sites. The accuracy of the developed numerical model is assessed through comparison of the predicted and measured responses of the test piles. This section presents the development of the numerical model for laterally loaded monopiles that has been employed throughout the project using the FE software ICFEP (Potts and Zdravkovic, 1999, 2001). An initial discussion is found in Zdravkovic et al. (2015).

A numerical model of any geotechnical problem under investigation is required to represent realistic geometry, ground conditions, boundary conditions and material behaviour; to be able to produce accurate predictions of its response to prescribed actions. The problem geometry in the PISA Project is that of a laterally loaded monopile, with geometric characteristics shown in Figure 1: the pile diameter, $D$, its embedded length, $L$, the height of the stick-up, $h$, and the pile wall thickness, $t$. The horizontal loading of a monopile implies a plane of symmetry in the problem geometry and it is therefore sufficient to discretise only half of the geometry into a FE mesh. Figure 7 shows an example of a typical FE mesh for a test pile in clay $(D=0.762 \mathrm{~m}, L / D=10)$.

The FE mesh contains three different domains: the soil, the pile and the pile-soil interface, which are all discretised with high-order displacement based isoparametric finite elements. The soil makes use of 20-noded hexahedral elements, the pile uses 8-noded shell elements (Schroeder et al., 2007) and the interface is discretised with special 16-noded zerothickness interface elements (Day and Potts, 1994). The interface elements are introduced around the outside of the pile to allow appropriate constitutive modelling of the pile-soil interface and to allow separation between the pile and the soil (primarily opening of a gap around the pile, which is the likely consequence of its lateral loading).

\subsection{Boundary conditions}

It is necessary to prevent rigid body movements of the FE mesh and this is achieved by setting to zero all three displacement components in the three coordinate directions ( $\mathrm{X}, \mathrm{Y}$ and $\mathrm{Z}$ ) at the base of the mesh. In addition, the displacements normal to the vertical cylindrical boundary are also set to zero, together with zero forces in the vertical Z-direction and directions tangential to this boundary. To ensure that the $\mathrm{X}-\mathrm{Z}$ plane at $\mathrm{Y}=0$ is a plane of symmetry, the displacements normal to this plane (i.e. in the Ydirection) are set to zero, as are the forces in the $\mathrm{X}$ and Z-directions. Additionally, the rotational degrees of freedom with respect to $\mathrm{X}$ - and $\mathrm{Z}$-axes along the edges of pile shell elements in the $\mathrm{Y}=0$ plane are also set to zero.

The horizontal load at the pile top, at $\mathrm{Z}=h$, is applied in a displacement-controlled manner, by prescribing increments of uniform displacement in

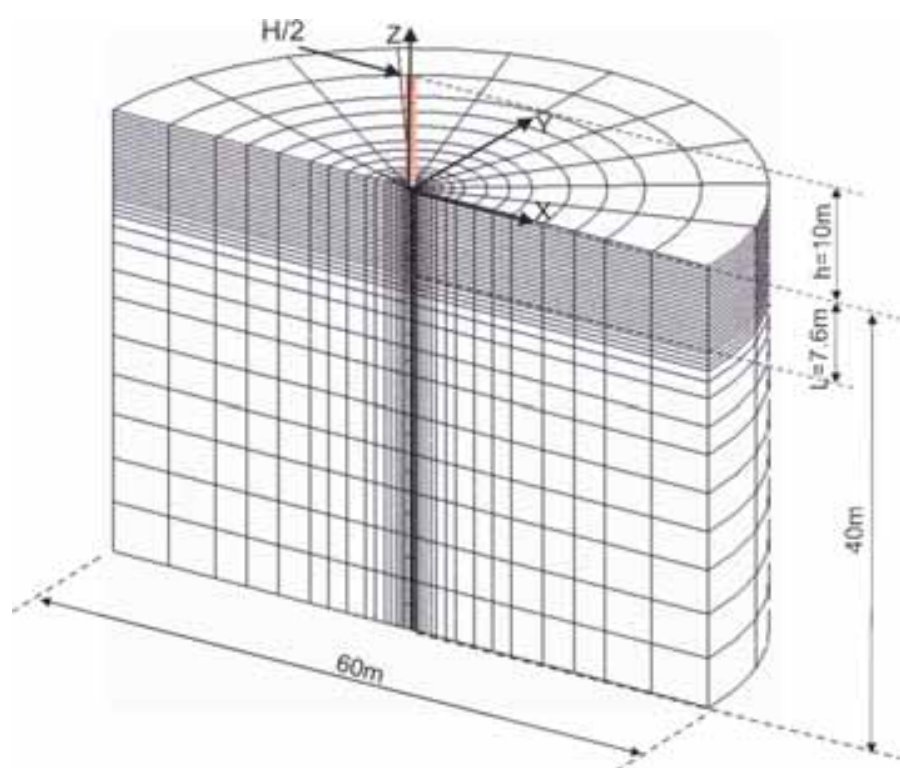

Figure 7: Typical FE mesh, showing the coordinate system employed in the analyses. 
the $\mathrm{X}$-coordinate direction around the pile perimeter. The horizontal load, $H$, at pile top is obtained as a reaction to the applied horizontal displacements.

\subsection{Ground conditions}

At the outset of the project a decision was made to ignore pile installation effects on initial ground conditions. It was considered that such effects are difficult to verify against realistic field conditions and would therefore present unknowns which are hard to quantify and to take proper account of in a numerical analysis. Consequently, the piles were modelled as "wished in place", in initially undisturbed ground conditions.

Setting the realistic initial ground conditions for an $\mathrm{FE}$ analysis generally requires the specification of the distributions of the vertical and horizontal effective stresses, over-consolidation ratio, pore water pressure and void ratio. A realistic input of these parameters is essential in establishing accurate profiles of the initial undrained strength, $s u$, relative density, $D_{R}$, or maximum shear modulus, $G_{0}$, for the soil that are consistent with the site investigation data. Usually a combination of field and laboratory ground investigations needs to be assessed for accurate derivation of initial ground conditions. Field testing, such as CPTu or seismic CPT profiling, is complemented by high quality soil sampling and laboratory testing. The maximum shear modulus profile could be interpreted from dynamic field techniques such as SCPT, or from the laboratory dynamic (bender element) and static (small strain instrumentation) measurements that are normally undertaken in triaxial apparatus.

\subsection{Material behaviour}

Three different materials are modelled in the FE analyses of PISA monopiles: the soil (overconsolidated glacial clay till and dense sand), the steel (pile) and the pile-soil interface.

For modelling monopiles under monotonic lateral loading, the soil constitutive model is required to accurately reproduce its small strain stiffness and conditions at failure. The former requirement is important for realistic simulation of the pile response at early stages of loading (i.e. the initial gradient of the load-displacement curve). The latter is required to compute realistic failure loads. The available site investigation and laboratory experimental data were insufficient for assessing the effect of soil anisotropy on its strength and stiffness and consequently the soil is modelled as an isotropic material.
The clay till material is modelled with an extended generalised Modified Cam clay (MCC) model of the type described in Tsiampousi et al. (2013). The behaviour of dense sand is reproduced with a bounding surface plasticity type model originally proposed by Manzari and Dafalias (1997), using here the modified version of Taborda et al. (2014). Both models are formulated within the critical state framework and can therefore reproduce conditions at failure. They can also accurately simulate the small strain nonlinearity of soil behaviour and can account for the variation of soil strength in the deviatoric plane. The clay model adopts the Hvorslev surface on the dry side of the critical state to account for realistic strengths of over-consolidated clays, which are otherwise over-predicted with the basic MCC model. The sand model accounts for realistic volumetric deformations of sands, contraction and dilation, which are dependent on the void ratio and stress level. Further details on these models can be found in Zdravkovic et al. (2015).

The pile-soil interface is simulated with elastoplastic constitutive models which have zero strength if loaded in tension and assume the compressive strength of the surrounding soil if loaded in compression. The former characteristic enables the opening of a gap around the pile during lateral loading.

The pile is considered linear elastic and its behaviour is described by the Young's modulus of 200GPa and a Poisson's ratio of 0.3.

\section{Field Testing}

The PISA Project plan set out a field testing campaign at a clay and a sand site to benchmark and validate the 3D FE modelling techniques, which are subsequently used to develop the design methodology. An initial description of the field test setup is given in Byrne et al. (2015b) and is further developed here. The primary objectives of these field tests were to:

- Examine in detail the load-deflection relationships for the pile-soil system, especially in areas important to design such as the pile-soil stiffness response and ultimate capacity;

- Determine the load distribution in the pilesoil system;

- Explore the effect of variations within a realistic geometric parameter space; and

- Examine the effects of cyclic loading through an additional phase of experimental work. 


\subsection{Specification and instrumentation}

In total 28 piles were tested with varied diameter, length and wall thickness with both monotonic and cyclic loads. The test layout was similar at each site and is shown in Figure 8. Up to 130 simultaneous instrument measurements of pile and soil response were acquired at sampling rates of $10-100 \mathrm{~Hz}$. The field tests, in themselves, represent a new industry standard database against which design models for piles in clay and sand may be compared and validated.

Ideally, full scale offshore tests of $6-10 \mathrm{~m}$ diameter piles would be used to benchmark the new design methodologies. However, due to the high cost of testing offshore and the technical constraints of the equipment that could be mobilised onshore, it was accepted that testing would be performed onshore at reduced scale. Scaled pile geometries and loading regimes were adopted, which were representative of offshore wind foundations including:

- Pile diameters of $0.273 \mathrm{~m}, 0.762 \mathrm{~m}$ and $2.0 \mathrm{~m}$;

- Embedded lengths between $1.43 \mathrm{~m}$ and $10.5 \mathrm{~m}$, providing a range of normalised length $3 \leq L D \leq 10$;

- Wall thicknesses $7 \mathrm{~mm}$ to $38 \mathrm{~mm}$, providing a range of normalised thickness $30 \leq D / t \leq 80$;

- Load application heights $5 \mathrm{~m}$ and $10 \mathrm{~m}$, providing load eccentricities $5 \leq M_{G} / H_{G} D \leq$ 18.3; and

- Predominantly monotonic load tests, supplemented with 1-way and 2-way cyclic loading.

The final selection of instrumentation was made in consultation with the main test contractor, ESG, to capture high quality data at the necessary range, resolution and sampling rate when measuring small and large displacements, as well as high frequency cycling. These instruments were chosen to measure both the above ground load-displacement response as well as the embedded pile-soil behaviour. A schematic of a fully instrumented $0.762 \mathrm{~m}$ diameter
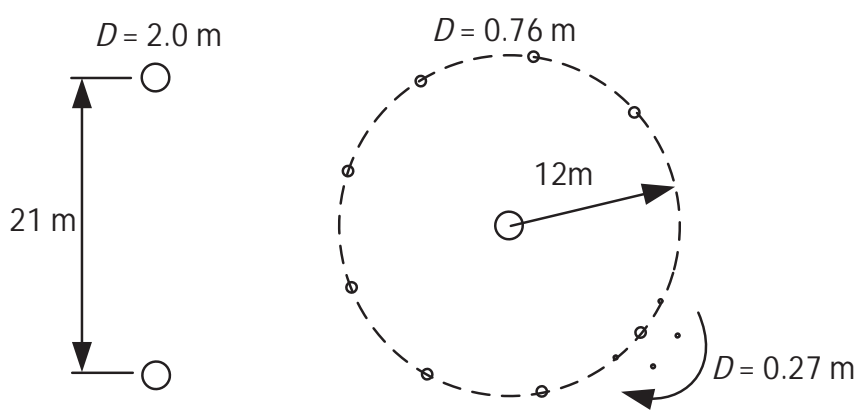

Figure 8: Pile testing layout at both sites.

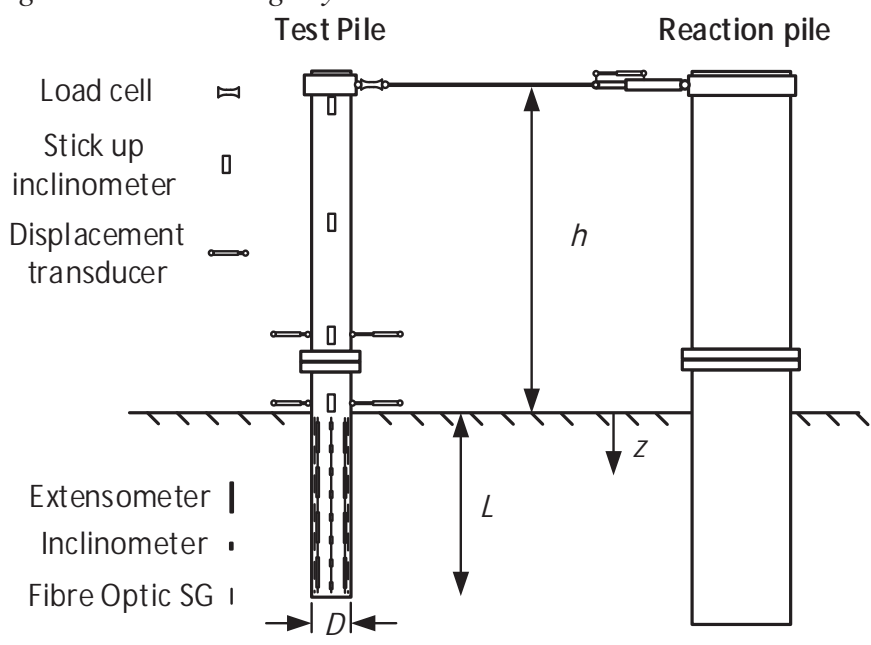

Figure 9: Medium diameter $(D=0.762 \mathrm{~m})$ test arrangement.

pile test is shown in Figure 9, including:

- Microelectromechanical system (MEMS) inclinometers to measure above ground rotation;

- Displacement transducers to measure above ground deflection;

- Load cells to measure the applied load and moment;

- Fibre optic strains gauges from which the embedded section bending moments are interpreted;

- Retrievable extensometers to act as a backup and validation of the fibre optic gauges;

- Retrievable inclinometers from which the embedded pile deflection is interpreted;

- Pore pressure transducers to measure dissipation prior to testing and response during testing; and
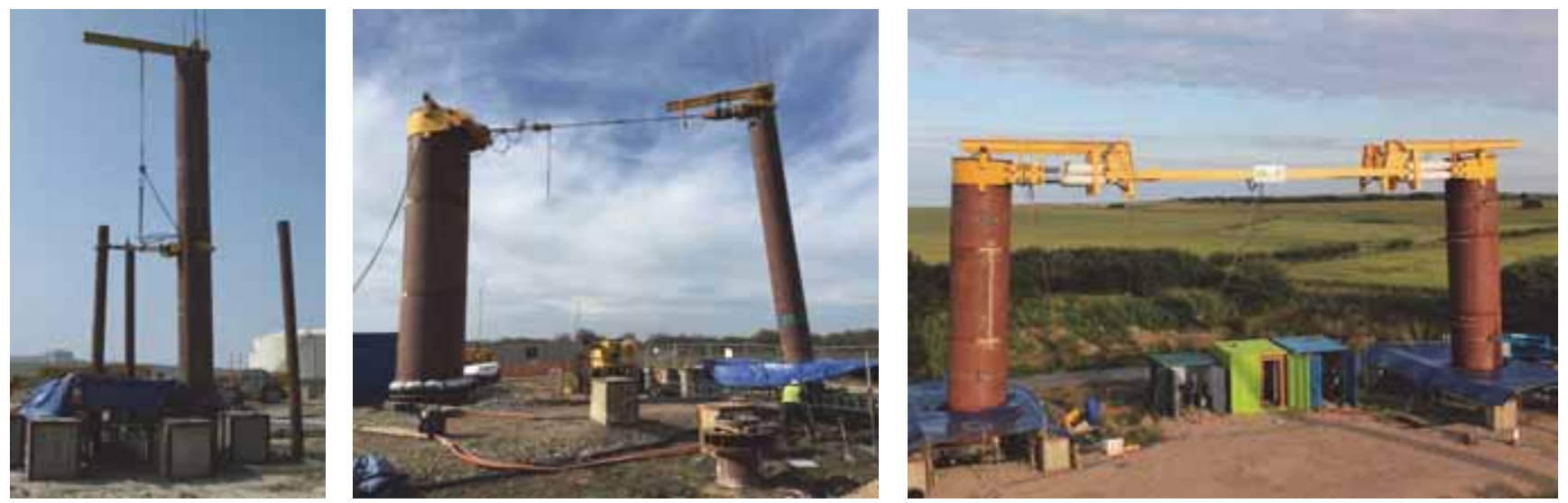

Figure 10: Images of the small $(D=0.273 \mathrm{~m})$, medium $(D=0.762 \mathrm{~m})$ and large $(D=2.0 \mathrm{~m})$ diameter test arrangements. 


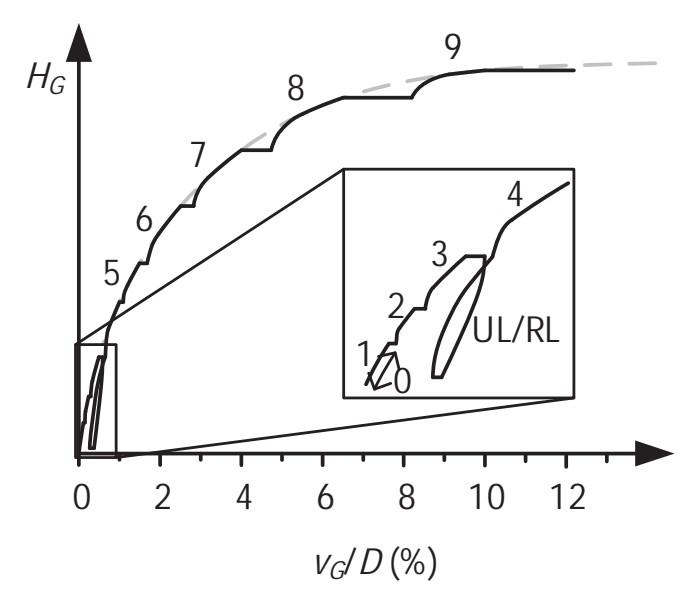

Figure 11: Field testing procedure.

- Thermometers for calibration of temperature sensitive instruments.

A set of photos of the field tests at different scales is shown at Figure 10. Within the design of the field tests, key tests were duplicated to provide redundancy in the event of a test failure. With the success of the main tests, the redundant piles were available to explore additional phenomena, such as the effect of a varied loading rate.

One of the most successful features of the field testing campaign was the use of fibre optic strain gauges to monitor both the installation and loading response of the driven test piles. The background to this approach is discussed in Doherty et al. (2015). The excellent resolution, stability and sensitivity of these instruments allow for the depth-wise variation of the embedded pile response to be accurately captured, and either integrated or differentiated obtaining other relevant quantities. New analysis techniques have been developed to interpret the measured data as it is recognised that the relationship between the soil reactions and the measured bending moment is more complex for short stubby piles compared to long slender piles.

\subsection{Test procedure}

The monotonic tests were generally conducted as constant velocity tests with periods of maintained load using the following routine (illustrated in Figure 11 where $v_{G}$ is the lateral ground level displacement):

(a) Before the main load test, an initial small displacement load-unload loop was performed to assess the small strain response and instrumentation performance. The pile was loaded up to a ground level displacement (approximated using feedback from the lower passive displacement transducer) of $D / 1000(0.1 \%$ of $D)$ at a ground level displacement rate of $D / 500$ per minute and the load held constant for a period of 5 minutes before unloading. During this time, checks were performed to ensure instruments functioned as expected.

(b) The main phase of the test was conducted by linearly increasing the ground level displacement at a rate of $D / 300$ per minute to a target displacement, as specified in Table 2 .

Table 2: Field pile load test procedure

\begin{tabular}{cccc}
\hline & & \multicolumn{2}{c}{$\begin{array}{c}\text { Normalised displacement } \\
v_{G} / D(\%)\end{array}$} \\
\cline { 3 - 4 } Step number & $\begin{array}{c}\text { Loading rate } \\
(/ \mathrm{min})\end{array}$ & Cowden & Dunkirk \\
\hline 0 & $D / 500$ & 0.1 & 0.1 \\
1 & $D / 300$ & 0.125 & 0.125 \\
2 & $D / 300$ & 0.25 & 0.5 \\
3 & $D / 300$ & 0.5 & 1.5 \\
Unload-Reload & $D / 500$ & - & - \\
4 & $D / 300$ & 1 & 2.5 \\
5 & $D / 300$ & 1.5 & 4 \\
6 & $D / 300$ & 2.5 & 5.5 \\
7 & $D / 300$ & 4 & 6.75 \\
8 & $D / 300$ & 6.5 & 8.25 \\
9 & $D / 300$ & 10 & 10 \\
Unload & $D / 500$ & & \\
\hline
\end{tabular}

(c) Once a desired ground level displacement increment was reached the load was maintained at that level until the displacement creep rate reduced to $D / 100,000$ per minute or for a maximum time of 30 minutes, before commencing the next load step.

(d) An unload-reload loop was performed after the load had been maintained at the $3^{\text {rd }}$ loading increment. During the unload-reload loop the load was reduced at a displacement rate of $D / 500$ per minute to approximately $10 \%$ of the load applied before the start of the unload loop. After a ten minute maintained load pause the pile was reloaded at a displacement rate of $D / 500$ per minute up to the previous maximum recorded load and maintained for a further 10 minutes before proceeding to the next load increment.

(e) If after the final load step, the rotation of the pile at ground level had not reached $2^{\circ}$, the pile was further displaced.

(f) Once the target displacement and rotation had been achieved, the pile was unloaded at a rate of $D / 500$ per minute after which the pile displacement was monitored for a period of approximately 30 minutes. 


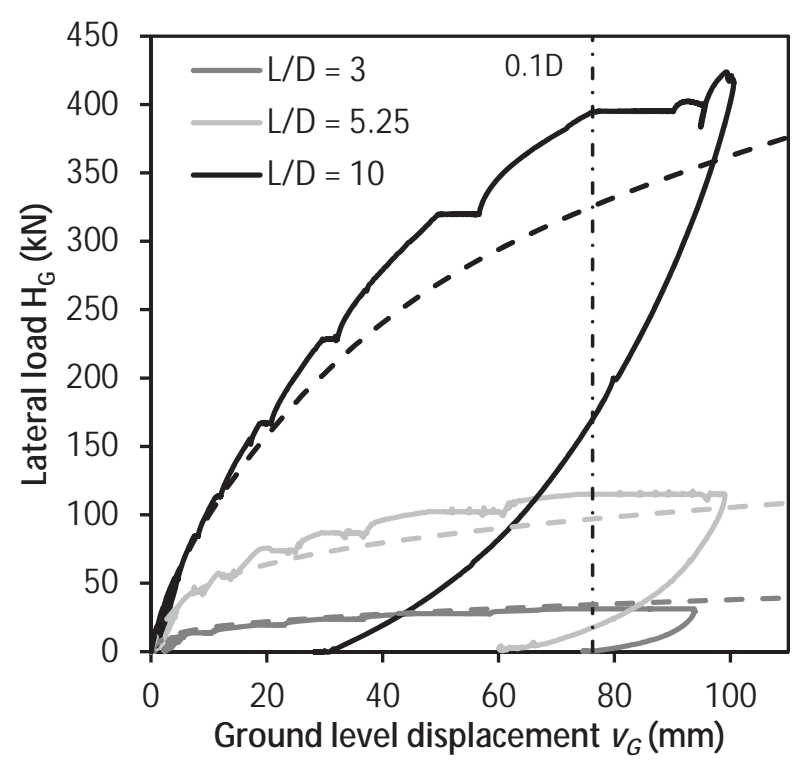

(a) Overall response

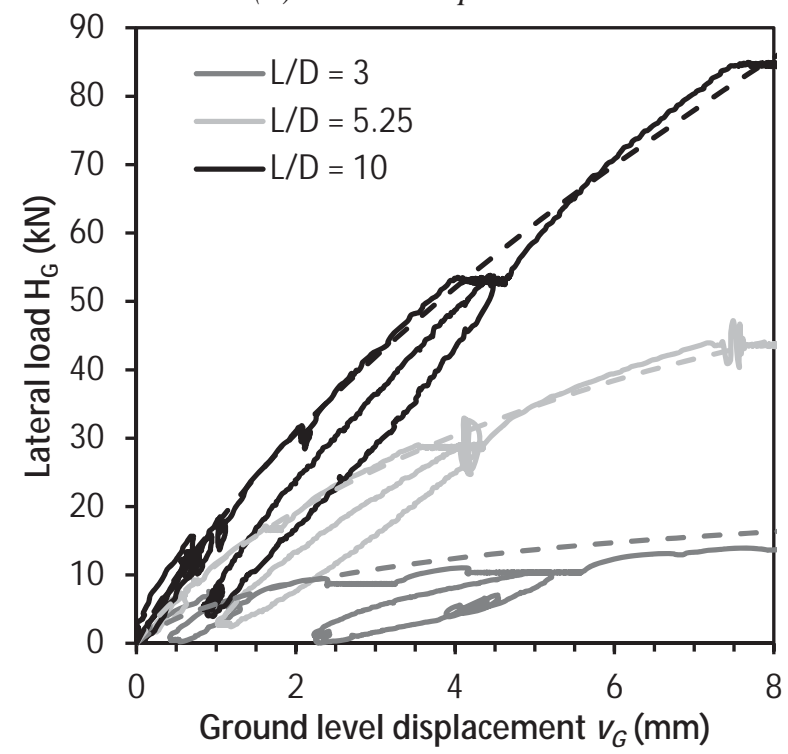

(b) Response at small displacement

Figure 12: Comparison of ground level load-displacement response for three $L / D$ ratios at $D=0.762 \mathrm{~m}$. Dashed lines represent the results of the $3 D \mathrm{FE}$ calculations.

For this project the definition of $D / 10$ displacement and 2 degrees of rotation at ground level was adopted for ultimate failure. Although these are "conventionally" adopted there is no rigorous basis for either.

\subsection{Example test results}

The field testing resulted in a substantial amount of data being gathered from both the above ground and the below ground instrumentation. This required a significant effort in calibrating, processing and interpreting. New analysis techniques were developed, particularly to determine the pile response at ground level. As the loading was applied at a substantial height above the ground, and there were no instruments measuring directly at ground level, it was necessary to perform a structural analysis of the system, combined with an optimisation procedure using the measured data

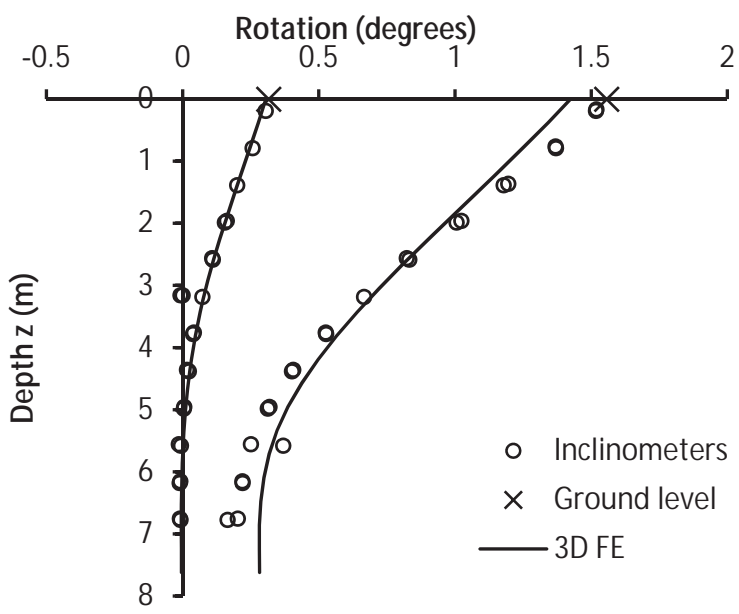

(a) Rotation profile

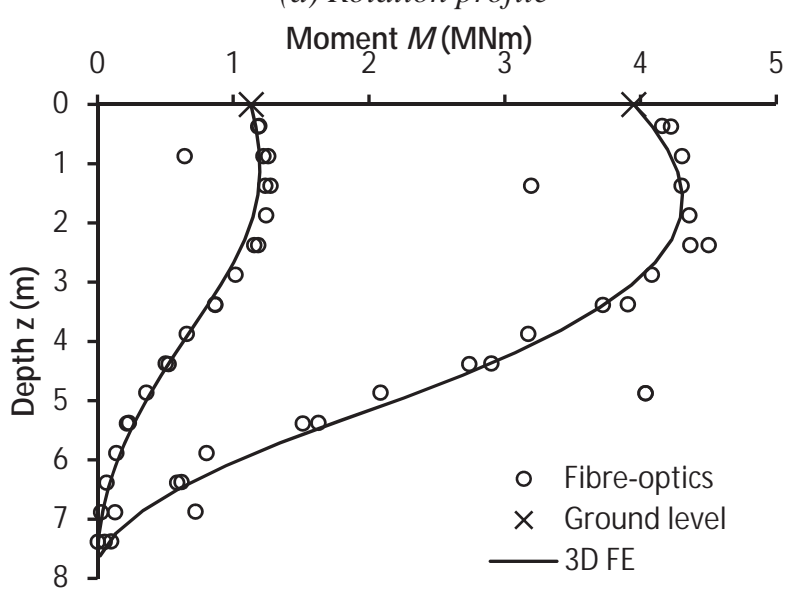

(b) Bending moment profile

Figure 13: Embedded response at $H=113 \mathrm{kN}$ and $395 \mathrm{kN}(D$ $=0.762 \mathrm{~m}, \mathrm{~L} / \mathrm{D}=10$ ).

(which includes redundant measurements) to deduce the ground level pile displacement and rotation.

Figure 12 highlights the processed test results for monotonic tests at Cowden for the $0.762 \mathrm{~m}$ diameter pile, with three different embedded depths. The overall response, to large displacement, as well as the initial response is shown. The load-displacement response shows clearly the creep that occurs when the load is maintained at the different load increments. On unloading and reloading there appears to be a marginally stiffer response, and on further loading there is more plasticity once the previous loads have been exceeded. Unloading at the end of the test saw significant recovery of displacement, particularly for the longer pile.

There is a defined relationship between embedment depth and both stiffness and capacity, as expected. The shorter pile shows more evidence of achieving a defined capacity whereas the longer pile continues to pick up capacity with displacement even at the defined failure displacement. It is evident from the load-displacement trace for the mid-length pile, which was tested near the beginning of the testing campaign, that the control algorithm for the 


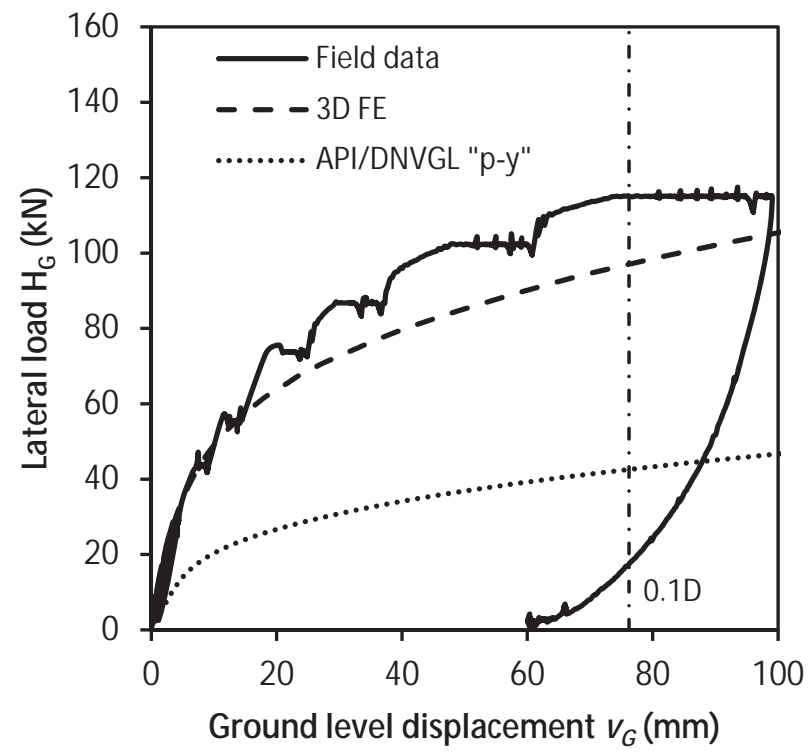

(a) Overall response

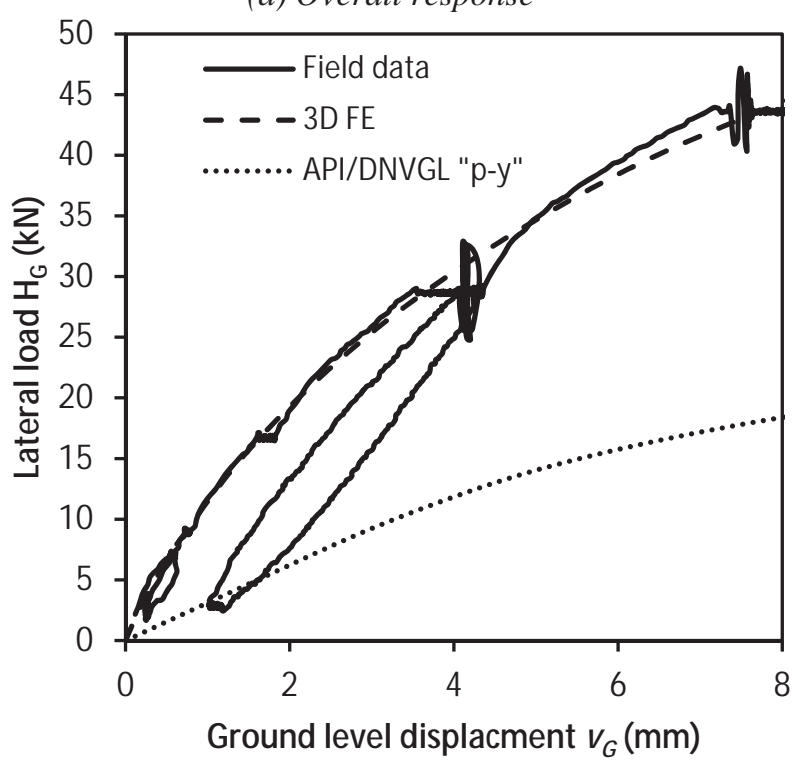

(b) Response at small displacement

Figure 14: Comparison of ground level load-displacement response for $L / D=5.25$ and $D=0.762 \mathrm{~m}$.

maintained load condition required further optimisation. This was improved for the other tests undertaken, as evidenced by the results in the figure. For these tests the load eccentricity $M_{G} / H_{G}=10 \mathrm{~m}$.

The numerical predictions from the developed 3D FE, produced before the completion of the field tests, are overlain on Figure 12 demonstrating the excellent match obtained from these calculations, particularly at small displacements.

Figure 13 shows the depth-wise distribution of information gathered from the embedded sensors, for discrete increments in time for the longest pile. Also plotted are the 3D FE predictions for matching ground level displacements and moments. There is an excellent match between the rotation deduced from the inclinometers and the ground level measurements, as well as with the $3 \mathrm{D}$ FE calculations. In Figure $13 \mathrm{~b}$ the bending moment distribution with depth is shown. This has been deduced from the fibre optic strain gauges, and again there is an excellent match with both the ground surface measurements and 3D FE predictions.

Figure 14 shows the ground level load-displacement comparison between the field test result for a $D=$ $0.762 \mathrm{~m}$ pile with $L / D=5.25$ and the numerical prediction using the developed 3D FE. In addition a prediction using current design guidance based on the traditional $p-y$ approach is provided, showing that this neither captures the initial stiffness nor the capacity, underestimating both by significant factors. This further reinforces the discussion presented in Byrne et al. (2015a) on shortcomings of current $p-y$ methods for large diameter monopiles in stiff, ductile, low plasticity clays.

\section{New Design Method}

As an outcome of the 3D FE analysis and the field testing, a new design method has been developed, based on a one dimensional (1D) analysis model of a monopile for monotonic loading. This 1D model employs several of the assumptions that are fundamental to the conventional $p-y$ approach (e.g. the adoption of the Winkler assumption to specify the soil-structure interaction behaviour and the representation of the pile as a series of embedded 1D beam elements). The PISA analysis model includes various extensions, to include additional soil-pile interaction components (referred to in the current modelling approach as 'soil reaction curves') that have been found to be significant for monopile foundations with relatively low length-to-diameter ratios. These extensions were originally described in Byrne et al. (2015a). To further develop this modelling approach, new forms of mathematical functions to represent the soil reaction curves, described in the current paper, have been developed. The current modelling procedure is limited to monotonic loading, although it is capable of being extended to model soil damping (for dynamic analyses) and cyclic loading.

Beneficially, the proposed design approach retains many of the advantages of the traditional $p-y$ method (e.g. fast computation time) while incorporating enhancements to improve the performance of the modelling approach for relatively low length-todiameter ratio monopiles. A criticism of the current $p-y$ approach is that the fundamental equations (the $p-y$ curves) have become deeply embedded within the various design specifications, with the consequence that the method has essentially become 'static'. In developing an improved approach, a key 
(a)

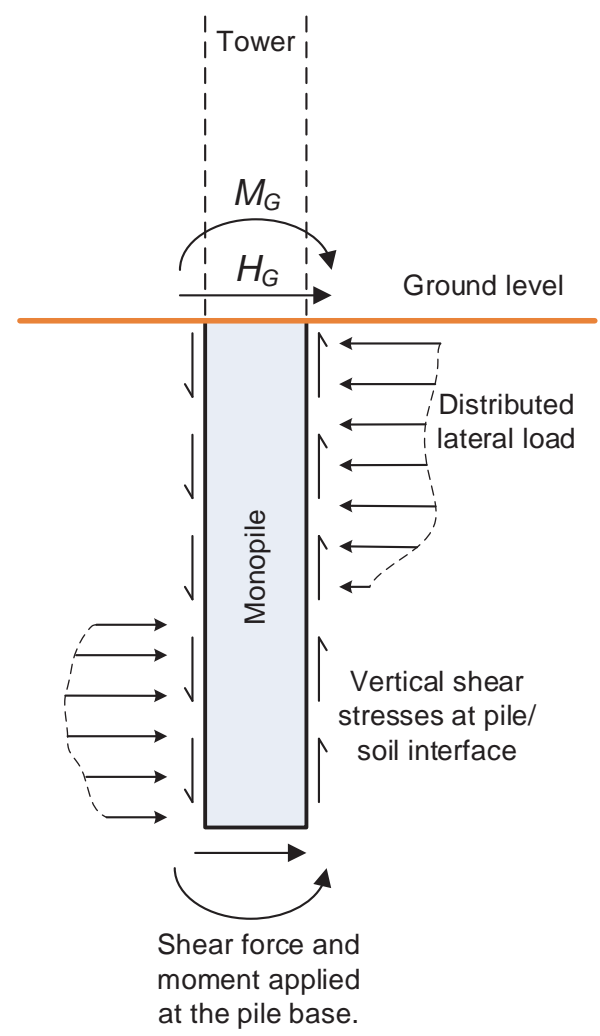

(b)

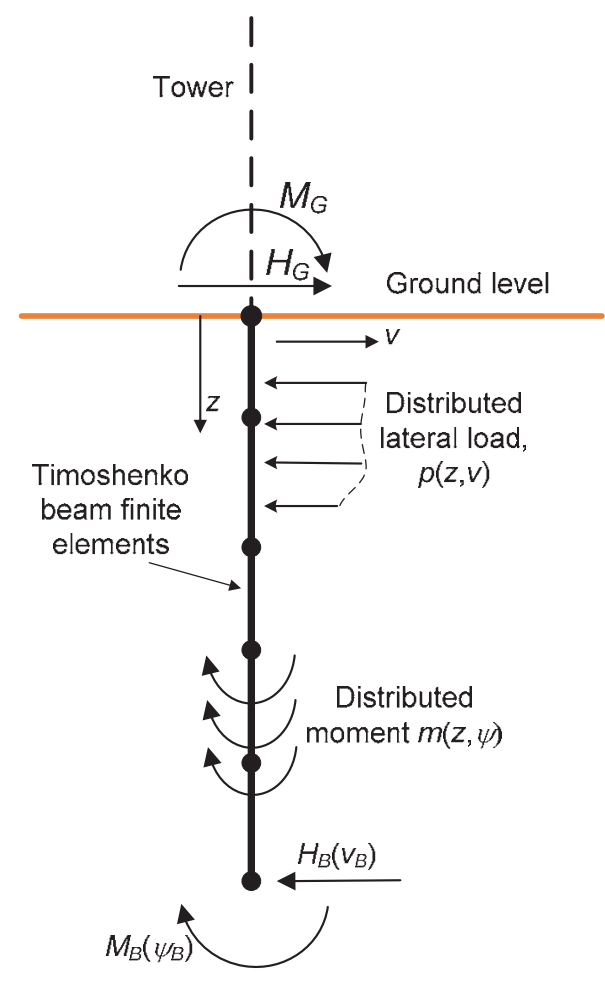

Figure 15: (a) Soil reaction components incorporated in the PISA design model. (b) 1D FE model employed in the PISA analysis model. Note that the indicated directions of the various soil reactions in (b) are consistent with the indicated coordinate system. This is in contrast to the diagrammatic approach in (a), in which the various reactions are shown acting in the directions that are actually expected to occur for the indicated loading.

principle that has been adopted is that the method should be capable of being further refined in the future, as further experience is gained on site investigation procedures, numerical analysis techniques and the observed behaviour of installed monopiles.

The proposed 1D analysis procedure is based on the assumed soil reaction components indicated in Figure 15(a), for the case where the monopile is loaded by the ground level horizontal force $H_{G}$ and moment $M_{G}$. Consistent with the conventional $p-y$ approach, a distributed lateral load is assumed to apply along the embedded length of the pile. In addition, the model includes vertical shear tractions that are induced on the pile perimeter. These shear tractions are associated with local pile rotation; in addition, near to the ground surface, significant vertical shear tractions are likely to develop on the passive side of the pile when the pile is loaded close to failure, as a consequence of the wedge-type mechanism that is expected to develop. These shear tractions, not included in the conventional $p-y$ method, become increasingly significant as the ratio of pile length to pile diameter reduces. The analysis model also includes a horizontal shear force and a moment reaction applied at the base of the monopile.

The conceptual model illustrated in Figure 15(a) is implemented in a 1D FE model of the embedded monopile as indicated in Figure 15(b). In this modelling approach the pile is represented as a line of beam finite elements, based on Timoshenko beam theory. Timoshenko beam theory incorporates, in an approximate way, the lateral pile displacements that occur due to shear strains, in addition to lateral displacements associated with bending action. Although current experience suggests that shear displacements are typically small, compared with bending displacements, the use of Timoshenko beam theory, rather than the more straightforward EulerBernoulli theory, provides an appropriate way of ensuring that any shear deformations that do develop are properly accounted for.

The local soil deformations (rotation and displacement) are prescribed to conform to the local pile displacements and rotations along the embedded length of the pile. The soil response is incorporated within the analysis, on the basis of the Winkler assumption, using appropriate mathematical models for the various soil reaction curves. Lateral soil reactions are represented by the curves $p(z, v)$, where $z$ is the vertical coordinate, $v$ is the local pile lateral displacement and $p$ has units of force/length. The action of the shear tractions shown in Figure 15(a) is represented in the analysis by a distributed moment, $m(z, \psi)$, where $\psi$ is the local pile cross-section rotation and the units of $m$ are moment/length. Reaction curves representing the horizontal base 
(a) Rule-Based Method

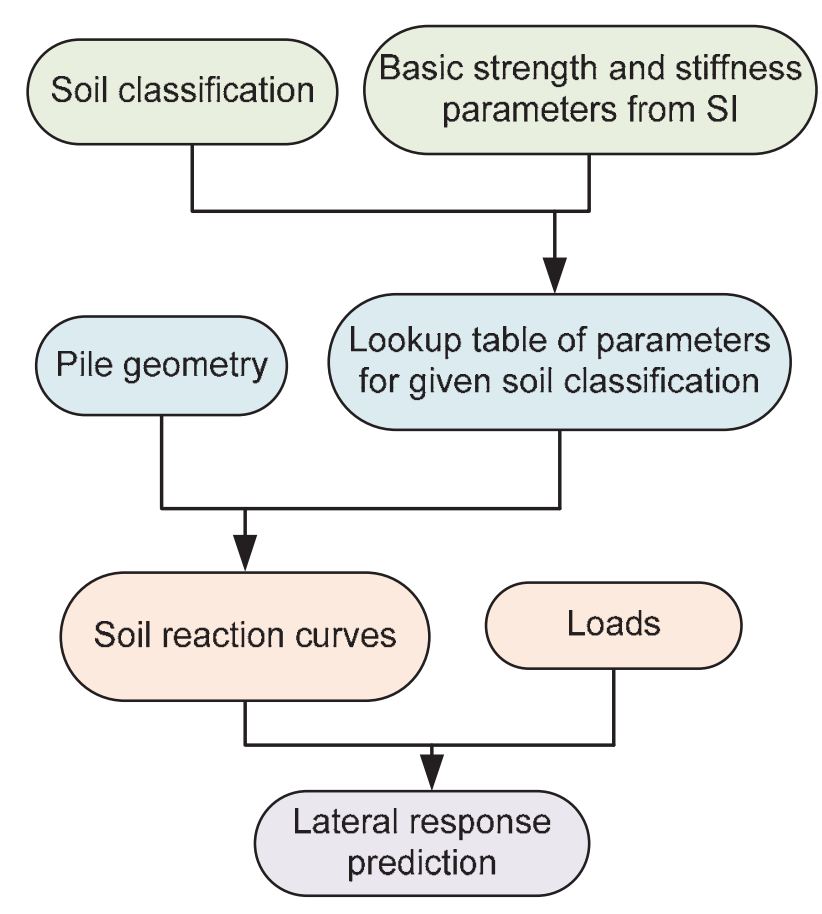

(b) Numerical-Based Method

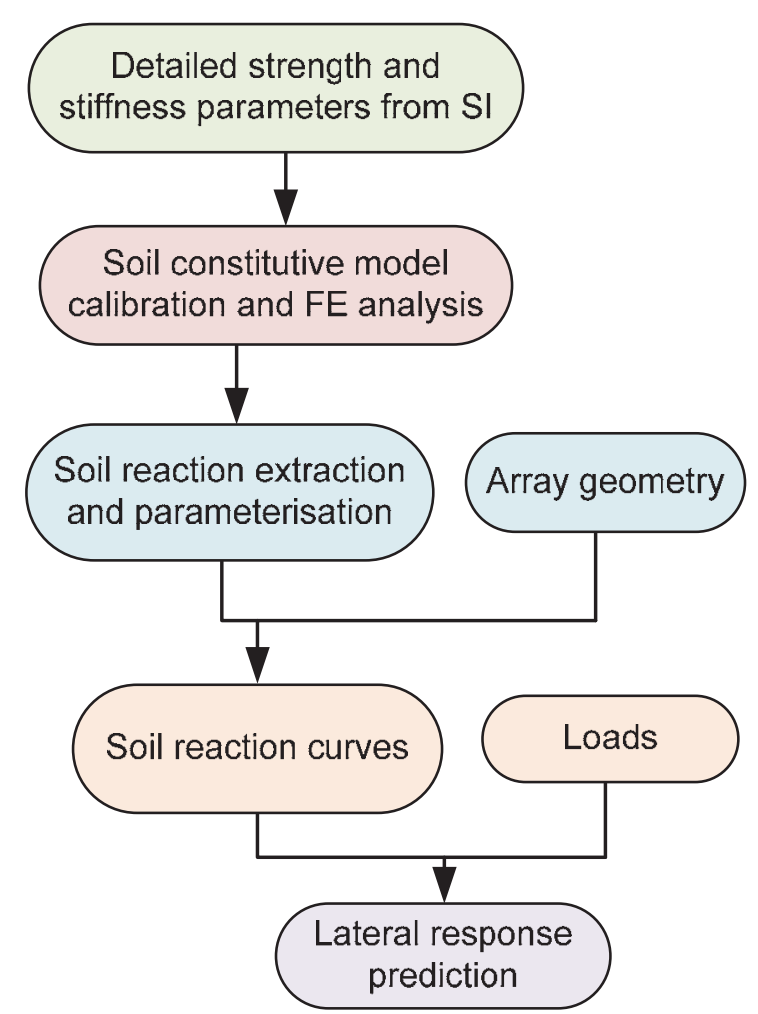

Figure 16: Application modes for the proposed design method: (a) rule-based method, and (b) numerical-based method.

force, $H_{B}\left(v_{B}\right)$, where $v_{B}$ is the lateral displacement at the base of the pile, and the base moment $M_{B}\left(\psi_{B}\right)$, where $\psi_{B}$ is the cross-section rotation at the base of the pile, are also included in the model.

Appropriate soil reaction curves for the application of the 1D analysis model to a particular design task can be determined using one of the two alternative procedures, as illustrated in Figure 16.

In the 'rule-based method', soil reaction curves are generated using pre-defined mathematical functions, with parameters determined from standard site investigation data (e.g. soil shear strength and stiffness). The soil reaction curves generated during the PISA Project (e.g. for Cowden clay and Dunkirk sand), as described below, could be used as rulebased equations in this context. These particular soil reaction curves were determined from 3D FE analyses for specific soil profiles (based on the Cowden and Dunkirk site data) and a range of typical pile geometries and values of loading eccentricity. The accuracy of the response prediction, when using these soil reaction curves for a new site, will be dependent on the similarity of the soil profiles and pile geometries with those employed in the original calibration exercise.

An alternative - potentially more versatile and accurate - approach, referred to as the 'numerical- based method' (Figure 16), involves the use of a 3D FE calibration study to establish bespoke soil reaction curves for a particular offshore site. Whilst the rule-based method is likely to be adopted for preliminary design activities in soils resembling Cowden clay till and Dunkirk sand, the numericalbased method will be applicable when different soil types are encountered and more detailed analyses are conducted at advanced stages of the design process.

To apply the numerical-based method, a procedure is envisaged in which results obtained from a suite of detailed 3D FE calibration analyses of monopile foundation behaviour are used in conjunction with high quality site investigations and soil testing to calibrate (or 'train') the (simpler) 1D FE model; the $1 \mathrm{D}$ model is then used to conduct the required design calculations. The 3D FE calibration analyses are based on detailed strength and stiffness data obtained from the site investigation process. These data are used to specify appropriate soil constitutive models for the site; these models need to be sufficiently sophisticated to be able to reproduce the soil response over an appropriate range of strains, and able to be calibrated with the available soil data.

The resulting 3D model is used to conduct a set of calibration analyses, based on representative ground conditions, pile dimensions and loading conditions. These calibration cases are required to span the 


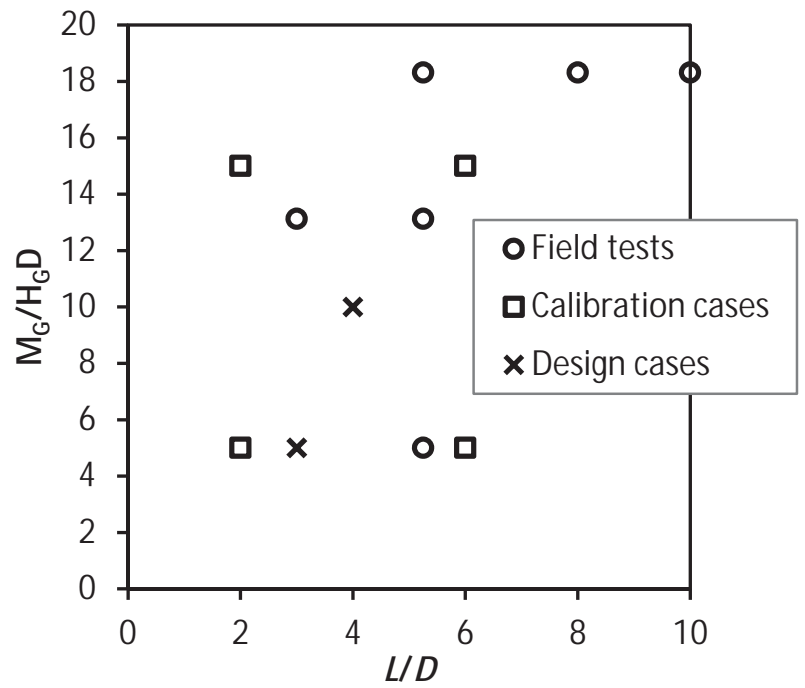

Figure 17: Parameter space of field tests, calibration cases and design case analysis.

design parameters (pile length, $L$, pile diameter $D$, and load eccentricity, $h$ ) of interest. The influence of pile wall thickness, $t$, is included explicitly within the beam elements employed in the 1D model and variations in this parameter do not need to be explored during the calibration process. Soil reaction curves are extracted from the results of the calibration analyses; these data are then normalised and parameterised. The parameterised forms are incorporated within the 1D FE model; the resulting 1D model is used to conduct the detailed calculations that are required by the design process for parameters that are within the calibration space.

It is important to emphasise the design philosophy that underpins the proposed numerical-based approach. In the conventional $p-y$ method, the $p-y$ curves are presented as a set of equations within a design guidance document. This approach means that the form of the curves cannot easily evolve as new soil constitutive models are devised or new site investigation procedures are developed. In contrast, the numerical-based approach provides a procedure in which the soil reaction curves employed in the 1D model are determined, directly, on a site-specific basis. This means that the approach can evolve with future developments in constitutive modelling and FE analysis. Design calculations can be conducted, rapidly and simply, using the calibrated 1D model; the accuracy of the 1D design calculation is comparable to that from more detailed 3D FE analyses. The proposed design approach comprises a process, and not just a prescriptive set of equations.

\subsection{Calibration parameter space}

To demonstrate the proposed modelling approach, 3D FE numerical modelling has been undertaken, using the models described in Section 3 and in Zdravkovic et al. (2015), for a typical range of

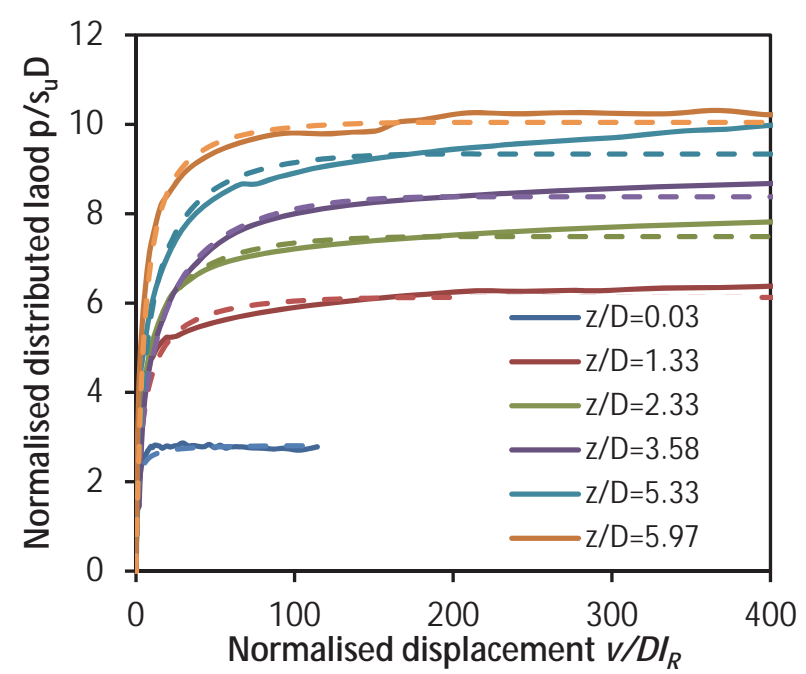

(a) Example soil reaction curves, for distributed lateral load, determined from the $3 D$ FE calibration case analysis $(D=10 \mathrm{~m}, L / D=6)$.

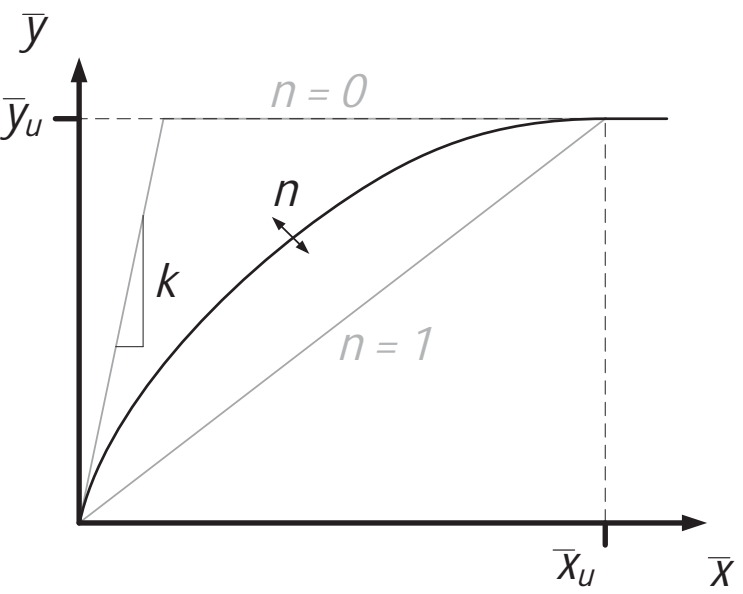

(b) Generic soil reaction curve

Figure 18: Detailed analysis of soil reactions.

monopile design parameters. These parameters are shown in Figure 17 for diameters ranging from $5 \mathrm{~m}$ to $10 \mathrm{~m}$ and indicated as 'Calibration cases'. These covered 11 different combinations of parameters including combinations of wall thickness. It was subsequently found that variations in pile wall thickness have negligible influence on the computed soil reaction curves. Also shown in Figure 17 are the 'Field tests' dimensionless groups, demonstrating that the field tests are consistent with the full-scale design problem represented by the calibration study. Also identified are two 'Design cases' based on arbitrary choices of pile parameters and load eccentricity within the calibration space, to provide test cases for the design method.

\subsection{Soil reaction extraction}

The detailed process of extracting the soil reaction curves from the 3D FE calibration cases is described in Byrne et al. (2015a), and is not further discussed here. For example purposes, a set of lateral soil reaction curves for Cowden clay (in which the lateral displacement is normalised using the dimensionless group in Table 1 and the lateral load, 


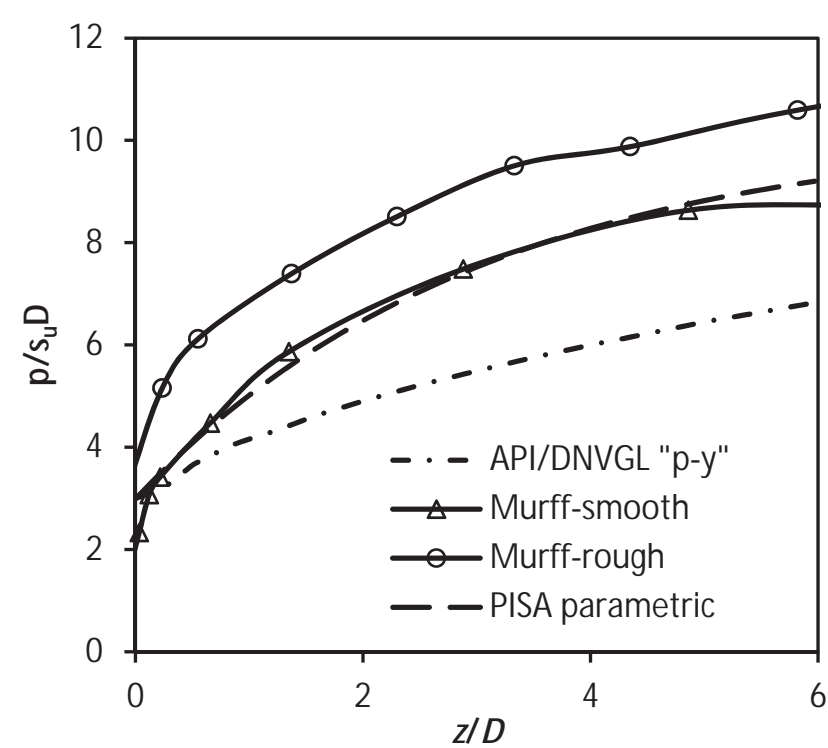

Figure 19: Distribution of ultimate normalised lateral soil reaction with depth for stiff clay soil profile.

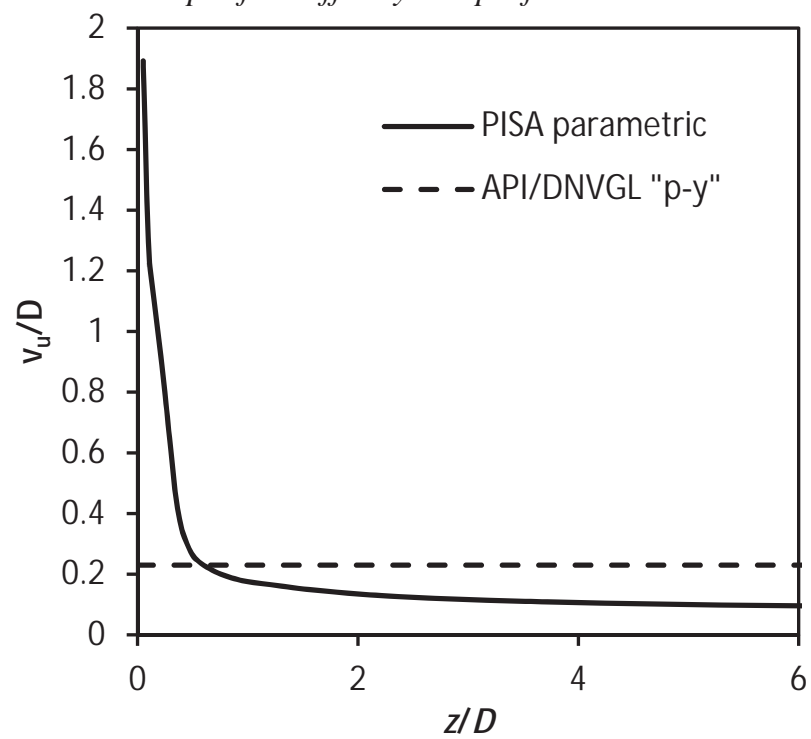

Figure 20: Distribution of normalised ultimate displacement with depth.

$p$, is normalised by dividing by the local shear strength and pile diameter) are shown in Figure 18(a) for a pile with $L / D=6$. As expected, the general magnitude of the lateral soil reaction tends to increase with increasing depth (i.e. increasing value of $z / D$ ).

The soil reaction curves extracted from the $3 \mathrm{D}$ analysis (shown as solid lines in Figure 18(a)) are represented in a general parameterised form using the conic function illustrated in Figure 18(b), where $\bar{x}$ refers to a normalised displacement variable and $\bar{y}$ is the corresponding normalised reaction variable. Each curve can be generalised by defining the four parameters shown on the figure to span the full range of behaviour needed for all four soil reaction curves employed in the model. An optimisation procedure is carried out to find the best-fit distribution of parameters for each of the soil reactions across all calibration calculations. The normalised parameterised curves, for the distributed

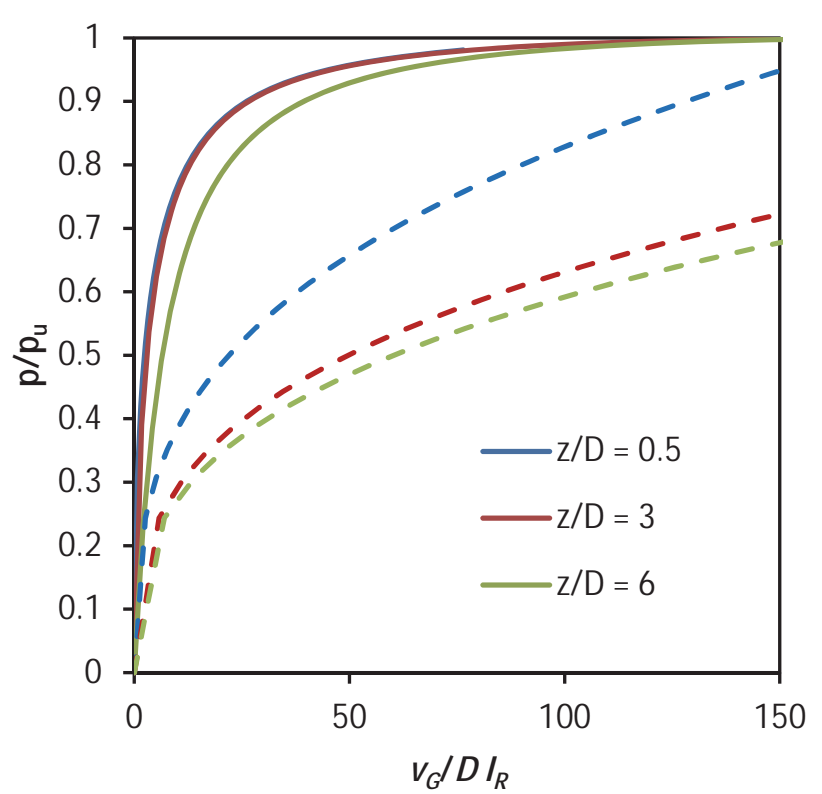

Figure 21: Comparison between PISA parametric (solid lines) and API/DNVGL p-y method (dashed lines) predicted lateral distributed load, normalised by the ultimate resistance, at various depths for a $10 \mathrm{~m}$ diameter pile.

lateral load case, are shown plotted as dashed lines in Figure 18(a).

\subsection{Comparison with existing methods}

The lateral load soil reaction curves reach a limiting value, $p_{\mathrm{u}}$, as the local soil displacement increases (e.g. see Figure 18(a)). Experience with the application of the 1D analysis method to monopile foundations has highlighted the importance of capturing the near-surface variation of $p_{\mathrm{u}}$ with depth. Figure 19 shows a comparison between the depthvariation function for $p_{u}$ computed from the calibration cases and the corresponding data from Murff and Hamilton (1993) for the translation of smooth and rough piles in a rigid plastic soil with uniform strength. Also shown is the equivalent variation of $p_{u}$ with depth specified in the typical API/DNVGL $p-y$ approach. The 'PISA parametric' results are broadly consistent with the Murff and Hamilton (1993) calculations, although the underlying methodology adopted by Murff and Hamilton is very different to the finite 3D FE approach used here. Values of $p_{u}$ computed using the API/DNVGL methods fall well below the other curves. Note that the Murff and Hamilton (1993) data shown are for weightless soil, whereas the 'PISA parametric' and 'API/DNVGL' curves shown in Figure 19 do account for soil weight.

Furthermore, the standard $p-y$ formulation indicates that the ultimate lateral resistance $p_{u}$ is not mobilised until a lateral displacement of approximately $v_{u}=$ $0.23 D$ (for all depths) for a soil with the properties of Cowden clay. This displacement is significantly higher (except at shallow depths) than the ultimate 


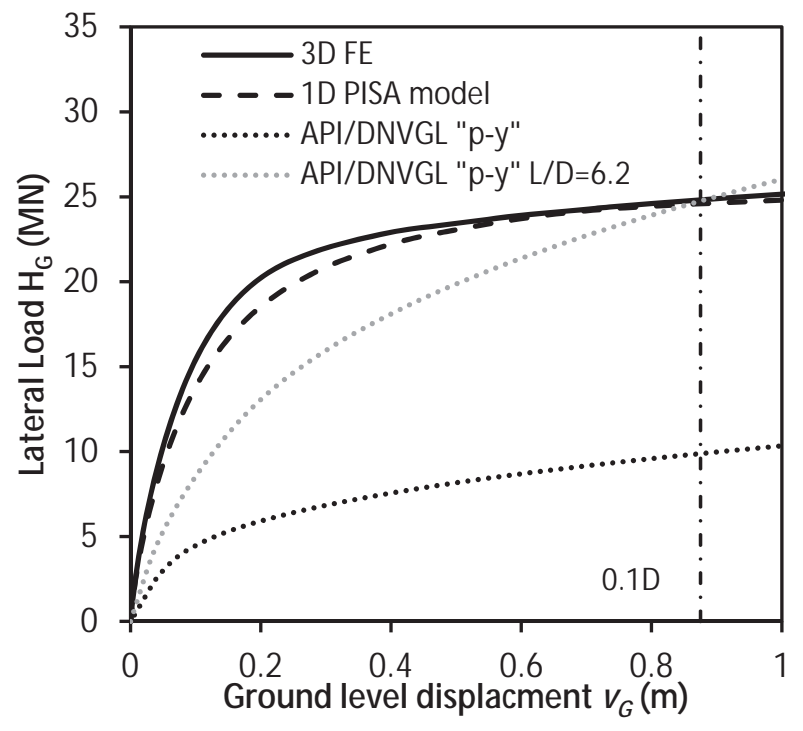

(a) Response to large displacements

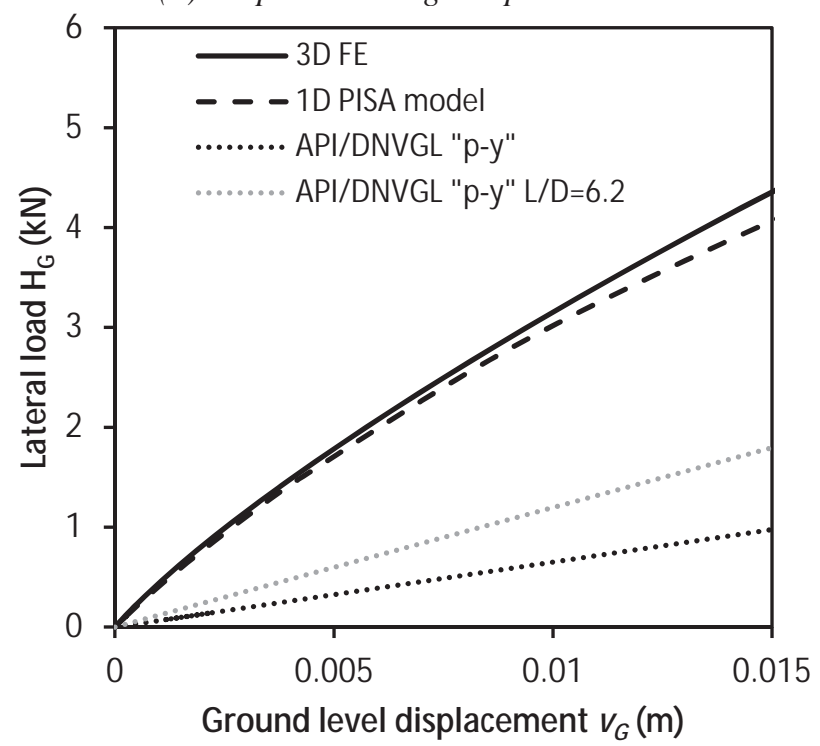

(b) Response at small displacement

Figure 22: Interpolation design case: $L / D=4, M_{G} / H_{G} D=10$ and $D=8.75 \mathrm{~m}$.

displacement typically observed in the parametric fit to the 3D FE calibration cases, as shown in Figure 20. Figure 21 compares predictions of how the lateral distributed load curves, normalised by the ultimate resistance, evolve with normalised displacement; this plot shows that the standard curves under-predict the displacement needed in the 3D FE model to mobilise the ultimate resistance. The tendency of the standard methods to underpredict the ultimate lateral resistance, combined with the relatively large values of displacement required to mobilise the ultimate resistance, are the principal causes of the tendency of the traditional approach to give a conservative estimate of overall pile response, compared with 3D FE analysis, for this particular stiff over-consolidated clay.

Finally the design cases illustrated in Figure 17 are returned to, for the particular case of $L / D=4$ and $M_{G} / H_{G} D=10$. This case was not included in the calibration set on which the 1D model was trained.
Instead the 1D PISA model was used to produce an analysis of the overall pile response, after which a 3D FE calculation was conducted for comparison purposes. The resulting data, shown in Figure 22, demonstrates that the 1D PISA model provides an excellent representation of the response of the monopile, as computed using the 3D FE model. A similarly close match is obtained for the second design case in Figure $17\left(L / D=3\right.$ and $\left.M_{G} / H_{G} D=5\right)$; this demonstrates the robustness of the proposed 1D analysis model, provided that it is employed within the calibration space. If the traditional $p-y$ methods are used to design a pile to have the same ultimate capacity (about $25 \mathrm{MN}$ ) the $L / D$ required would be 6.2 ; the pile would be $55 \%$ longer than determined using the PISA approach. Even with this increased length, as indicated on Figure 22(a), the response would be significantly softer at small displacements than determined using the PISA method.

\section{Routes for application}

\subsection{Application of the rule-based method}

The rule-based equations for the soil reaction curves are determined in non-dimensional form. To apply them to a specific design task, data are needed on the variation with depth of the small-strain shear modulus $G_{0}$ at the site of interest. In addition, for a clay soil, values of triaxial compression undrained shear strength, $s_{u}$, are required. From the constitutive formulation of the sand material studied in this project, the $G_{0}$ profile also reflects the initial density profile of the deposit and a further input is needed on the variation of in-situ vertical effective stress with depth. However, this approach could be expanded to employ the peak or critical state angle of shearing resistance, depending on the chosen constitutive formulation.

Values of $G_{0}$ are conveniently measured using seismic cone tests. Data on undrained shear strength may be determined either using cone penetration testing (based on appropriate $N_{k t}$ values) or advanced triaxial testing on high quality samples. Ideally, a profile of undrained shear strength at the site of interest is developed on the basis of a combination of data from triaxial testing and CPT results. Data on in situ vertical effective stress may be estimated on the basis of soil unit weights assessed from relative densities determined by cone penetration tests.

\subsection{Application of the numerical-based method}

The numerical-based method requires the use of a 3D FE model of the monotonic behaviour of a monopile foundation subjected to a lateral load and moment; the 3D FE model is used to conduct a suite 


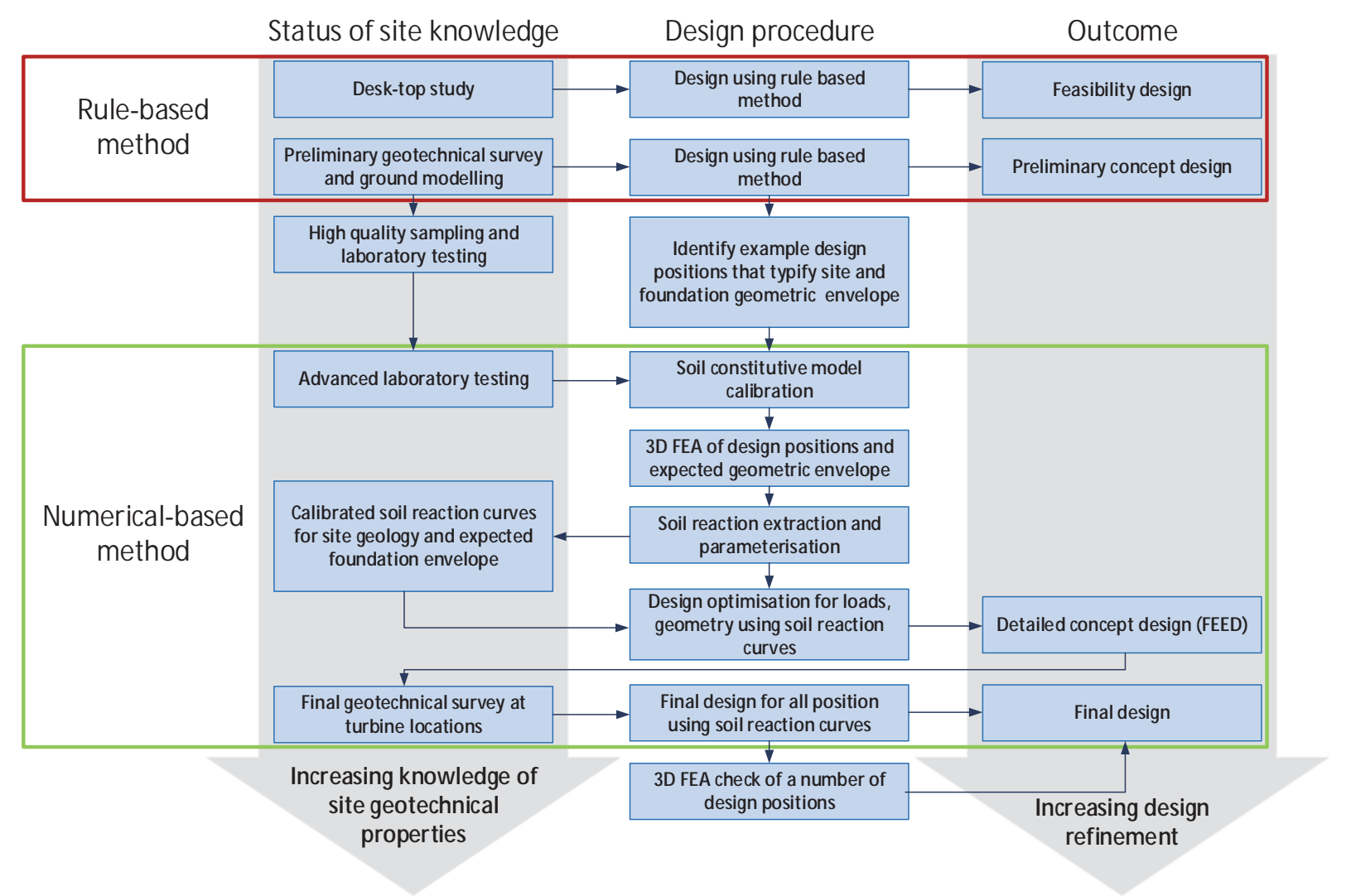

Figure 23: Application of the new analysis procedure in the overall design process.

of calibration analyses, within the likely range of relevant design parameters $\left(L, D\right.$ and $\left.M_{G} / H_{G} D\right)$. 3D FE calibration analyses should make use of the symmetry of the problem to minimise the size of the mesh. Boundaries should be placed sufficiently far from the monopile to ensure that they do not affect the results. It may be appropriate to conduct some initial studies to investigate such effects. The pile should be modelled using shell elements with zerothickness interface elements placed between the soil and the pile. The interface elements provide a means of specifying the behaviour of the soil-pile interface as well as providing a means of extracting the soil reaction curves from the analysis.

Careful selection is needed of the soil constitutive model if reliable results are to be obtained. It may be necessary (in cases where an advanced soil model is selected) to employ a finite element platform in which user-specified constitutive models can be employed. For clay, the soil is expected to behave in an undrained manner for short-duration loading; soil models in this case can be based either on a total stress approach (in which case the site-specific variation of undrained shear strength is a direct input to the constitutive model) or an effective stress approach (in which case the effective stress soil parameters need to be defined as a direct input to the model, with undrained strength being indirectly defined from these parameters). For sands, an effective stress model is required, which captures the volumetric characteristics of the soil (dilation / contraction) at an appropriate level of detail.

For the design of a monopile to achieve a specified stiffness (e.g. to determine the natural frequencies of a wind turbine at low levels of excitation) it may be sufficient to adopt an elastic model for the soil. A simple approach might be to assume that the soil is linearly elastic, with a variation of shear modulus with depth determined from the results of seismic cone tests. A more sophisticated approach would be to assume a non-linear elastic model incorporating an appropriate degradation of shear modulus with shear strain level. In this latter case, advanced triaxial testing incorporating local strain measurement is required to determine the appropriate stiffness degradation curve.

For cases where design calculations are required in which the monopile is loaded to failure, the 3D FE calibration analyses need to be based on an appropriate elastic-plastic model for the soil. For clay, the generalised Modified Cam clay model in Tsiampousi et al. (2013) (employed in the current work) provides one possible approach. For sand, the bounding surface model in Papadimitriou and Bouckovalas (2002) and Taborda et al. (2014) could be used. The use of advanced soil models of this sort inevitably means that further detail on soil behaviour is required for calibration purposes. Variations with depth of $K_{0}$ and pore pressure are invariably required. In addition, further detailed laboratory tests 
(e.g. triaxial extension tests) may be needed to determine the required model parameters (e.g. shape of the model's yield surface in the deviatoric plane). Prior to conducting detailed 3D calibration analysis, it is advisable to conduct simple, introductory, analyses (e.g. a laterally-loaded monopile using a relatively simple built-in soil model)

Books such as Potts and Zdravkovic (1999, 2001) and Brinkgreve (2013) provide background information on the modelling approaches available.

\subsection{Design procedures}

An approach for applying the PISA design method in design is shown in Figure 23, which would comply with DNVGL (2016) requirement to validate soil reaction curves for monopiles by FE analysis. For initial feasibility design, the rule-based method would be applied. In this case, preliminary site investigation data would be gathered to support the concept design, developed using the rule-based method. Information from this preliminary design process would assist in the specification of the site investigation and laboratory testing program needed for the final design process.

The concept design and site investigation data would identify the parametric space that the 3D FE calibration analyses (required for the numericalbased method) should span. The calibrated 1D model will allow the monotonic response of the pile to be determined for any pile within the calibration space. It is noted that the calibration space adopted in the PISA Project, as described here, was deliberately broad. In a practical design context for an actual wind farm, the range of the parameters employed in the calibration analysis could be significantly reduced; this will minimise the number of calibration calculations required and also maximise the reliability of the calibrated 1D model. The site-specific soil reaction curves applied to the 1D model will allow site specific optimisation of each monopile at each location. Finally, it may be appropriate to check one or two final designs with a specific 3D FE calculation, to confirm the overall robustness of the design process. This general approach reflects the likelihood that the level of geotechnical detail available to the design process will develop as the geotechnical knowledge of the site (gained from site investigation, laboratory testing and bespoke 3D FE modelling) increases.

It should be noted that the evolution of the design procedures from the existing $p-y$ method to the more robust and complete design approach described in this paper, will have differing levels of impact on the ULS, SLS and FLS design cases. Careful thought should therefore be given to the confidence intervals of soil properties and partial factors applied in each case, to ensure a safe, but not over-conservative design.

Finally, although the PISA approach has been applied here to large diameter monopiles the general principles can be applied to a wide range of foundation types including to define more appropriate lateral soil reactions for standard jacket piles and for suction caisson foundations.

\section{Limitations}

There are limitations to the application of the design approaches developed through the PISA Project. At the outset the following principles were agreed:

(a) To consider two specific homogeneous soil profiles, as representative soil profiles for offshore wind farm sites. Application of the specified rulebase methods to other soil profiles will require further analyses and engineering judgment to be applied. Additional work will be required to further develop the numerical-based methods for other soil profiles, with this paper outlining a structured design process through which the detailed design equations for the soil reaction curves can be obtained. The consideration of new soil profiles, and in particular layered soil profiles, is the subject of ongoing research through an extension to PISA.

(b) To consider monotonic loading only. This provided a significant focus to the project, with the result that the initial stiffness and ultimate capacity of the pile have been clearly defined. Although some of the field testing involved cyclic loading, there was limited interpretation of the cyclic response during the PISA Project.

(c) To neglect the effects of installation on the pile response. The new design method is based on the results from an application of the 3D FE method, which represents the current state-of-the-art in numerical modelling. However, modelling of installation effects still provide a considerable challenge, and addressing this was beyond the scope of the project. Differences between field test results and the numerical calculations could highlight what such effects might be, and whether they are significant.

These limitations were necessary to focus the scientific activity on delivering engineering 
solutions to the funding partners in the timescale required by the project. Engineering judgment will be required to use these methods in practice, as is the case with the application of any design method.

In addition, it should be noted that the soil reaction curves determined from a calibration study at a particular site may be sensitive to the detailed way in which the geotechnical parameters vary with depth. For offshore sites at which significant variation in geotechnical parameters is expected across the site, then it may be necessary to conduct separate calibration studies - to support the use of the numerical-based method - for selected site locations.

\section{Conclusions}

The aim of the PISA Project was to investigate and develop improved design methods for laterally loaded piles, specifically tailored to the offshore wind sector. The approach adopted by the Academic Work Group was to validate 3D numerical models using medium scale field tests. These models were then used to investigate the performance of the existing $p-y$ design method and to form the basis for developing an improved method capable of accurately capturing the behaviour of laterally loaded piles under load cases critical to design.

The work of the PISA Project supports the following high level findings:

(a) The standard $p-y$ method (e.g. API, 2010) provides an unsatisfactory basis for the design of wind turbine monopile foundations, especially those with low $L / D$ ratios and for stiff low plasticity ductile clay soils where stiffness and capacity appears under-predicted when considering realistic geometries.

(b) A new approach is proposed in which the traditional $p-y$ approach is enhanced by the inclusion of additional soil reaction curve components (distributed moment, horizontal base force and base moment). A process is outlined in which $3 \mathrm{D} \mathrm{FE}$ analyses are used to calibrate the soil reaction functions, which can then be applied, within a simplified 1D model, to pile geometries and soil conditions that fall within the calibrated parameter space. This approach benefits from the computational speed of the traditional $p-y$ approach while retaining a comparable accuracy to the underlying 3D FE model. The application of this design approach indicates potential for a significant reduction in design conservatism and substantial savings for selected design scenarios. (c) A medium scale field testing campaign was carried out in which a total of 28 piles were tested with varied diameter, length and wall thickness with both monotonic and cyclic loads and with up to 130 simultaneous instrument measurements of pile and soil response. These field tests, and the supporting site characterisation, deliver a new industry standard database against which design models in clay and sand may be compared, developed and validated.

(d) Adoption of the PISA design approach is likely to result in reduced conservatism in monopile design and better economies for wind farm development. It is important that as these methods are adopted, consideration is given to realistic design drivers for the foundations, including effects of cyclic loading on strength, stiffness and accumulated deformation.

Although PISA has focused on monopiles the numerical-based methods described have much wider application including, for example, to larger $L / D$ piles (such as for jackets) and for suction caisson foundations.

\section{Acknowledgements}

The PISA Project was funded by the UK Department for Energy and Climate Change (DECC) and the PISA Industry Partners under the umbrella of the Offshore Wind Accelerator (OWA) program which was designed and is led by the Carbon Trust. The Authors acknowledge the provision of financial and technical support by the following project partners: Alstom Wind, DONG Energy, E.ON, EDF, Iberdrola, innogy, SSE, Statkraft, Statoil, Van Oord and Vattenfall. The Authors also acknowledge the assistance of John Powell and the BRE for the use of the Cowden site.

\section{References}

API. (2010). RP 2A-WSD - Recommended practice for planning, designing and constructing fixed offshore platforms. Washington: American Petroleum Institute.

Brinkgreve, R.B. (2013). Validating numerical modelling in Geotechnical Engineering. NAFEMS.

Byrne, B.W., McAdam, R., Burd, H.J., Houlsby, G.T., Martin, C.M., Zdravkovic, L., ... Skov Gretlund, J. (2015a). New design methods for large diameter piles under lateral loading for offshore wind applications. Proc. $3^{\text {rd }}$ Intern. Symp. of Frontiers in Offshore Geotech., Oslo.

Byrne, B.W., McAdam, R., Burd, H.J., Houlsby, G.T., Martin, C.M., Gavin, K., ... Skov Gretlund, J. (2015b). Field testing of large diameter piles 
under lateral loading for offshore wind applications. Proc 15 th European Conf on Soil Mech and Geotech Engng., Edinburgh.

Chow F.C. (1997). Investigations into the behaviour of displacement piles for offshore foundations. $\mathrm{PhD}$ thesis, Imperial College, London.

Cox, W. R., Reese, L. and Grubbs, B. R. (1974). Field testing of laterally loaded piles in sand. Proc. Offshore Technology Conference, Houston.

Davidson, H.L. (1982). Laterally loaded drilled pier research, Vol 1: Design methodology, Vol. 2: Research documentation. Final Report by GAI Consultants Inc. to Electric Power Research Institute (EPRI).

Day, R.A. and Potts, D.M. (1994). Zero thickness interface elements - numerical stability and application. Int. Jnl. Num. Analy. Meth. Geomech. 18: 689-708.

DNVGL. (2016). DNVGL-ST-0126 - Support structure for wind turbines. Oslo: Det Norske Veritas.

Doherty, P., Igoe, D., Murphy, G., Gavin, K., Preston, J., McAvoy, C., ... Skov Gretlund, J. (2015). Field validation of fibre Bragg grating sensors for measuring strain on driven steel piles. Géotechnique Letters 5: 74-79.

Gerolymos, N., and Gazetas, G. (2006). Development of Winkler model for static and dynamic response of caisson foundations with soil and interface nonlinearities. Soil Dynamics and Earthquake Engineering 26 5: 363-376.

Jardine, R.J, Standing, J.R and Chow, F.C. (2006). Some observations of the effects of time on the capacity of piles driven in sand. Géotechnique 55 4: 227-244.

Kelly, R.B., Houlsby, G.T. and Byrne, B.W. (2006). A comparison of field and laboratory caisson tests in sand and clay. Géotechnique 56 9: 617-626.

Lam, I.P.O. (2013). Diameter effects on $p-y$ curves. Deep Marine Foundations - A Perspective on the Design and Construction of Deep Marine Foundations.

Lam, I.P.O. and Martin, G.R. (1986). Seismic Design of High-way Bridge Foundations. US Department of Transportation Report No. FHWA/RD-86/102.

Leblanc, C., Byrne, B.W. and Houlsby, G.T. (2010). Response of stiff piles to random two-way lateral loading." Géotechnique 60 9: 715-721.

Lehane, B. M and Jardine, R. J. (1994). Displacement pile behaviour in glacial clay. Canadian Geotechnical Journal 31 1: 79-90.

Manzari, M.T. and Dafalias, Y.F. (1997). A critical state two-surface plasticity model for sands. Géotechnique 47 2: 255-272.
Matlock, H. (1970). Correlations for design of laterally loaded piles in soft clay. Second Annual Offshore Technology Conference, Houston.

Murff. J.D. and Hamilton J.M. (1993). P-Ultimate for undrained analysis of laterally loaded piles. ASCE Journ. of Geotech. Engng 119 1: 91-107.

Papadimitriou, A. G. and Bouckovalas, G. D. (2002). Plasticity model for sand under small and large cyclic strains: a multiaxial formulation. Soil Dyn. and Earthquake Engn 22 3: 191-204.

Potts, D. M. and Zdravkovic, L. (1999). Finite element analysis in geotechnical engineering: theory. London, Thomas Telford.

Potts, D. M. and Zdravkovic, L. (2001). Finite element analysis in geotechnical engineering: application. London, Thomas Telford.

Powell, J. J. M. and Butcher, A. P. (2003). Characterisation of a glacial clay till at Cowden, Humberside. In: T. e. al., ed. Characterisation and Engineering Properties of Natural Soils. Lisse: Swets and Zeitlinger, pp. 983-1020.

Reese, L., Cox, W. R. and Koop, F. D. (1974). Analysis of laterally loaded piles in sand. Proc. Offshore Tech. Conf., Houston.

Reese, L.C. and Matlock, H. (1956). Nondimensional solutions for laterally loaded piles with soil modulus assumed proportional to depth. Proc. 8th Texas Conf. on Soil Mech. and Found. Engng, Austin, TX.

Schroeder, F.C., Day, R.A., Potts, D.M. and Addenbrooke, T. I. (2007). An 8-node isoparametric shear deformable shell element. Int. Jnl of Geomechanics 7 1: 44-52.

Taborda, D.M.G., Zdravković, L., Kontoe, S. and Potts, D.M. (2014). Computational study on the modification of a bounding surface plasticity model for sands. Computers and Geotechnics 59: 145-160.

Tsiampousi A., Zdravkovic L. and Potts D.M. (2013). A new Hvorslev surface for critical state type unsaturated and saturated constitutive models. Comp. and Geotechnics 48: 156-166.

Winkler E.(1867). Die lehre von elasticitat und festigkeit, (H. Dominic us), Prague, 182-184.

Zdravković, L., Taborda, D.M.G., Potts, D.M., Jardine, R.J., Sideri, M., Schroeder, F.C., ... Skov Gretlund, J. (2015). Numerical modelling of large diameter piles under lateral loading for offshore wind applications. Proc $3^{\text {rd }}$ Intern. Symp. of Frontiers in Offshore Geotech., Oslo. 